\title{
Finite element approach toward an advanced understanding of deep rolling induced residual stresses, and an application to railway axles
}

\author{
S.M. Hassani-Gangaraj ${ }^{\mathrm{a}, \mathrm{b}, *}$, M. Carboni $^{\mathrm{b}}{ }$, M. Guagliano ${ }^{\mathrm{b}}$ \\ a Department of Materials Science and Engineering, Massachusetts Institute of Technology, Cambridge, MA 02139, USA \\ ${ }^{\mathrm{b}}$ Department of Mechanical Engineering, Politecnico di Milano, Milan 20156, Italy
}

\section{A R T I C L E I N F O}

\section{Article history:}

Received 29 January 2015

Revised 1 April 2015

Accepted 2 June 2015

Available online 19 June 2015

\section{Keywords:}

Railway axles

EA4T

Deep rolling

Finite element

Hole drilling

X-ray diffraction

Residual stress

Fatigue crack propagation

\begin{abstract}
A B S T R A C T
A full-scale railway axle, made of medium strength steel EA4T and adopted for high-speed applications, is deep rolled. The induced residual stresses were experimentally characterized by X-ray diffraction and hole drilling. A realistic finite element model is proposed to overcome some of the existing shortcomings in simulation of deep rolling. Deep rolling coverage is defined, formulated and incorporated into the simulation. The model is validated by the experimental measurements. A parametric study is performed to investigate the effect of rolling force $(4-19 \mathrm{kN})$, rolling feed $(0.1-0.7 \mathrm{~mm} / \mathrm{rev})$ and roll geometry $(1.5-10 \mathrm{~mm}$ roll tip radius) on the distribution of residual stresses and the induced hardening. A fatigue crack propagation algorithm is used to analyze the influence of the technological parameters on the lifetime of railway axles. Lower feeds, higher loads and thicker rolls, all resulting in higher coverage, can result in higher improvement against fatigue crack propagation. However, extremely high coverage can deteriorate the performance of deep rolled components. Coverage can effectively serve as a master parameter in deep rolling. As a general rule of thumb, adopting deep rolling feed to get a coverage level of $500-900 \%$, while avoiding too high rolling loads and too thin rolls, can induce a suitable compressive residual stress distribution; and effectively prevent/retard fatigue crack propagation.
\end{abstract}

๑ 2015 Elsevier Ltd. All rights reserved.

\section{Introduction}

Deep rolling is a surface treatment where roll or ball-point tools are used to press the target surface. As the roll sweeps the surface, the latter is plastically deformed and a groove is created. The elastic recovery of material, surrounding the plastic zone, produces compressive residual stresses in the surface layers. Deep rolling should be distinguished from roller burnishing, which mostly aims to enhance surface roughness quality by applying much lower forces. Indeed, deep rolling is aimed to extend component's fatigue life by generating compressive residual stresses. Deep rolling is applied on crankshafts, valve shafts, screws, bore-holes, axles, bolts and threaded parts in automotive industries, general mechanical engineering and, to a certain extent, in aerospace industries [1].

Large depth of the affected layer, exhibiting sufficient work hardening and compressive residual stresses, as well as generation of glossy surfaces with low roughness is the advantage of deep rolling with respect to other surface treatments [2]. For instance, the typical depth of the compressed layer in shot peening or

\footnotetext{
* Corresponding author at: Department of Materials Science and Engineering, Massachusetts Institute of Technology, Cambridge, MA 02139, USA.

E-mail address: mhassani@mit.edu (S.M. Hassani-Gangaraj).
}

nitriding is a few hundred micrometers [3,4] while deep rolling is able to extend the compressed layers more than $1 \mathrm{~mm}$ deep [5].

Rolling force or pressure, rolling feed, roll geometry, material, contact conditions and number of overruns are the important factors of a deep rolling treatment. Among them, force or pressure is believed the most influential one [2]. Only optimized rolling forces could increase the fatigue strength of deep rolled components; as too low rolling forces have no pronounced effect on the fatigue strength and too high forces might be even detrimental by inducing micro-cracks.

A large body of experimental research to characterize microstructure [6], cyclic deformation [7,8], fatigue [6,9-11], fretting [12], wear [13], thermal stability [14] and residual stress relaxation [15-17] of deep rolled components is available in the literature. However, a thorough analysis of the residual stress itself, as one of the most important outcomes of the process, is somewhat missing. Quantitative description of deep rolling usually aims to obtain residual stress distribution. Nonlinearities arisen from material behavior, surface conditions and large displacements limit the application of analytical approaches. Finite element analysis could be an effective alternative to overcome such complexities. A few attempts have been made for the similar treatment of fillet rolling. Chien et al. [18] simulated residual stress distributions using a 2D 
plane strain elastic-plastic finite element analysis. Rolling depth of the fillet surface, experimentally measured by the shadowgraphs taken before and after the fillet rolling, was used as the boundary condition under a deformation-controlled procedure. Spiteri et al. [19] assumed that the induced residual stress was greatly affected by the rolling force in the ramping up and down stages. In another word, additional operation in the full load stage was considered not to significantly increase the magnitude, or alter the distribution of the residual stress. In their model, a 2D plane strain target was loaded up to a maximum by the roll and then unloaded to drive the residual stress. The same assumption was also made elsewhere $[20,21]$. Majzoobi et al. [12] presented a 3D finite element simulation of a flat target rolled by a rigid body. However, the residual stress field predicted by the model was not compared with the experimental measurements to evaluate the accuracy of the simulation. The present shortcomings in the simulation of deep rolling will be addressed in this work by developing a more realistic finite element model.

Notwithstanding the significant role of residual stress for a successful deep rolling, the present work aims to provide a comprehensive insight using both experiments and simulations. The target component is a full-scale railway axle for high speed applications. Railway axles are one of the most critical mechanical components as regards safety. The railway axles are usually designed for an infinite life using admissible stress levels, which corresponds to generous safety factors applied to full-scale fatigue properties of materials [22,23]. Nevertheless, some failures still occur due to fatigue cracks generated during service, by corrosion-fatigue phenomena or ballast impacts [24-26]. In order to avoid such failures, which are related to a number of factors not easily predictable (see for example [27]), a suitable inspection strategy is supported by "damage tolerant" analyses [28-30]. A quite novel possibility is to consider the application of compressive residual stresses at the surface of the axles. Compressive residual stresses decrease crack propagation driving forces. This solution is mainly applied to freight applications nowadays, and also to high-speed ones in some European countries. A successful example, related to railway axles, is the application of induction hardening to increase the fatigue strength of the press-fit seats, where typically suffer from fretting-fatigue $[31,32]$. Other surface treatments like oxynitrocarburizing and shot peening were affirmed to have beneficial effects on fatigue limit of railway axle steels [33,34]. However, those have not been tested on a full-scale axle.

The present study explores the feasibility of performing deep rolling on full-scale railway axles. Generated surface residual stresses were measured by X-ray diffraction (XRD) and hole-drilling (HD) methods along the axle axis. In depth measurement of residual stress distribution was also carried out at different selected locations. The depth of the hardened layers was also characterized by XRD. A realistic finite element simulation of deep rolling is developed and validated. Accordingly, a parametric study is performed to study the effect of rolling force, rolling feed, roll geometry and also deep rolling coverage on the distribution of residual stresses and the induced hardening. Finally, the obtained parametric residual stress profiles are introduced in a simple crack propagation algorithm to analyze the influence of the technological parameters on lifetime of railway axles, by both "one-parameter-a t-a-time" and "Design of Experiments" methodologies.

\section{Material and experiments}

\subsection{Material}

The material considered in this study is the EA4T (quenched and tempered 25CrMo4) steel grade, one of the standardized European steels used for the production of railway axles [35]. Its nominal chemical composition [24] is summarized in Table 1. The mechanical properties were evaluated through monotonic, low-cycle fatigue (LCF) and crack propagation tests.

\subsection{Monotonic and cyclic behavior}

Monotonic tensile tests were carried out following the suggestions given by the ASTM E8 standard [36]. Two dog-bone cylindrical specimens were tested by an electro-mechanical mono-axial machine with a $100 \mathrm{kN}$ load cell and an extensometer. The experimental monotonic stress-strain curves of the material are shown in Fig. 1a, while Table 2 summarizes the obtained mechanical properties as the mean value of the two tests.

Seven dog-bone specimens were subjected to strain-controlled fatigue tests to obtain the low cycle fatigue (LCF) behavior of the material. The tests were carried out using a servo-hydraulic mono-axial machine with a $100 \mathrm{kN}$ load cell and an extensometer at $R=-1$ and at a frequency of $1 \mathrm{~Hz}$. The tests were carried out following the suggestions given by the ASTM E606 standard [37] adopting the "single step" methodology. The strain ranges applied to the seven specimens were $\pm 0.23 \%, \pm 0.27 \%, \pm 0.3 \%, \pm 0.4 \%, \pm 0.5 \%$, $\pm 0.6 \%$ and $\pm 0.7 \%$. The cyclic curve was derived (Fig. $1 \mathrm{~b}$ ) by interpolating the tips of the stabilized, i.e. acquired at half the fatigue life of each specimen, hysteresis loops. Accordingly, the RambergOsgood relationship (Eq. (1)) was adopted for the present material.

$\varepsilon=\frac{\sigma}{E_{c}}+\left(\frac{\sigma}{H}\right)^{1 / n}$

The obtained empirical parameters $E_{c}, H$ and $n$ are shown in Table 2 together with the cyclic yield stress $R_{p 0.2 c}$. The derived cyclic curve is compared to the monotonic ones in Fig. 1a, where a significant softening behavior of the material can be observed during cyclic loading.

\subsection{Crack propagation behavior}

Due to the superposition of compressive residual stresses and in-service rotating bending, the stress ratio acting at the surface of the axle will be different, in particular much lower than the typical $R=-1$ value adopted in rotating bending test. From this point of view, a dedicated experimental campaign was carried out, in order to investigate the crack propagation behavior of the EA4T grade in the not-yet-explored region of very negative stress ratios. Full details of this activity are reported in [38], while a short summary of the tests is as follow. Specimens with single edge in bending, $S E(B)$, and single edge in tension, $S E(T)$, were prepared and tested using the compression pre-cracking approach $[39,40]$. $\mathrm{SE}(\mathrm{B})$ specimens were tested at different stress ratios ranging from $R=0.7$ to $R=-2.5$. In order to obtain relevant results for even more negative stress ratios, $\mathrm{SE}(\mathrm{T})$ specimens were tested at different stress ratios ranging from $R=-2.5$ to $R=-4$. All data were then interpolated by Nasgro equations [41] for the FCG lifetime predictions described in Section 4.4.

\subsection{Deep rolling of full-scale railway axle}

The scheme of the full-scale railway axle studied in this work, and typically adopted for high-speed applications, is shown in Fig. 2a. The axle was deep-rolled along the body (including

Table 1

Nominal chemical composition of EA4T steel grade (weight \%).

\begin{tabular}{llllllllll}
\hline $\mathrm{C}$ & $\mathrm{Mn}$ & $\mathrm{Si}$ & $\mathrm{Cr}$ & $\mathrm{Mo}$ & $\mathrm{Ni}$ & $\mathrm{V}$ & $\mathrm{S}$ & $\mathrm{Cu}$ & $\mathrm{Pa}$ \\
\hline $0.22-0.29$ & $0.5-0.8$ & $0.15-0.4$ & $0.9-1.2$ & $0.15-0.3$ & 0.3 & 0.06 & 0.015 & 0.3 & 0.02 \\
\hline
\end{tabular}




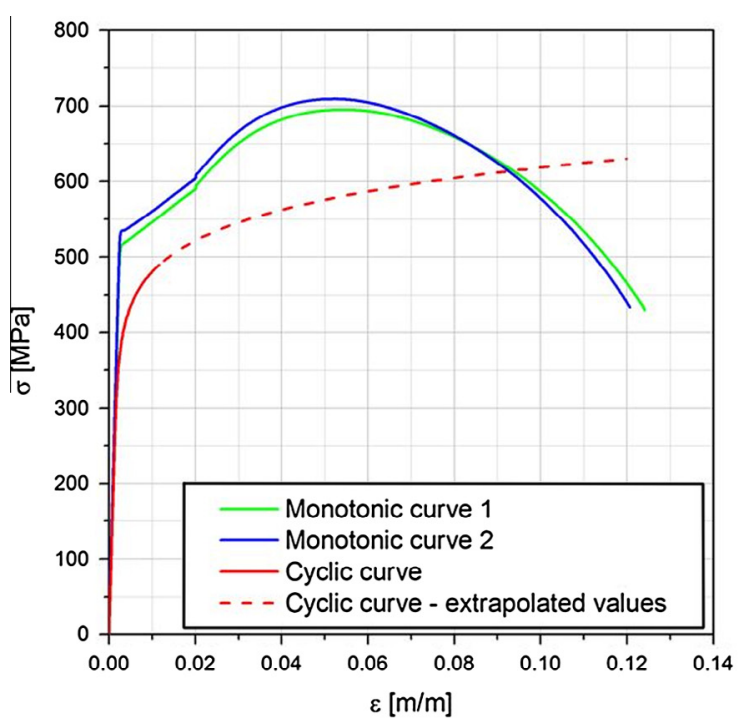

(a)

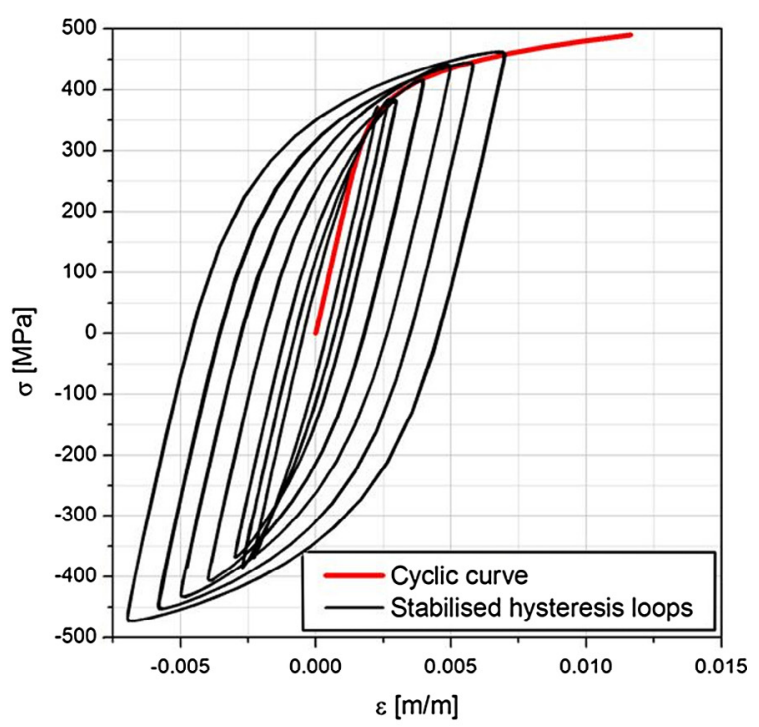

(b)

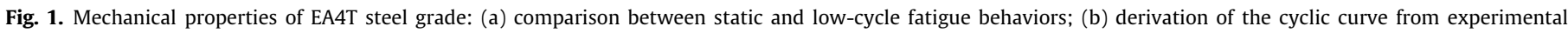
stabilized hysteresis loops. $R=-1$ and frequency of $1 \mathrm{~Hz}$ were applied for cyclic tests.

Table 2

Experimental monotonic and cyclic properties of EA4T steel grade.

\begin{tabular}{ll} 
Monotonic properties & \\
Modulus of elasticity E (MPa) & 209,726 \\
Yield stress $R_{p 0.2}(\mathrm{MPa})$ & 531 \\
Ultimate tensile stress (MPa) & 702 \\
Elongation (\%) & 12.2 \\
Poisson's ratio & 0.3 \\
Cyclic properties & \\
Cyclic modulus of elasticity $E_{c}(\mathrm{MPa})$ & 194,200 \\
Cyclic yield stress $R_{p 0.2 c}(\mathrm{MPa})$ & 422 \\
$H(\mathrm{MPa})$ & 778.6 \\
$n$ & 0.099 \\
\hline
\end{tabular}

transitions) and all the seats of wheels and disk-brakes, but not along the bearing journals. Deep rolling was carried out using an $85 \mathrm{~mm}$ diameter roll. The thickness of the roll and its curvature at the tip were $5 \mathrm{~mm}$ and $2.5 \mathrm{~mm}$ respectively; that is to say the roll had a semi-circular tip shape. The rolling pressure was kept constant during the treatment providing a rolling force of approximately $7 \mathrm{kN}$. Longitudinal feed was set to be $0.15 \mathrm{~mm} / \mathrm{rev}$, and the axle revolution frequency was estimated to be around $4 \mathrm{~Hz}$.

\subsection{Residual stress measurements}

The residual stress pattern in the surface layers of the deep rolled full axle, was measured using two different experimental approaches: X-ray diffraction (XRD, [42]) and hole drilling (HD, [43]). The latter is one of those suggested by the relevant standard for railway axles [24]. The details on their application and the obtained results are described in the following sections.

\subsubsection{X-ray diffraction method}

XRD analysis was performed using an AST X-Stress 3000 X-ray diffractometer. Lattice deformation of $\{211\}$ diffraction planes of the $\alpha$-Fe phase were measured using $\mathrm{Cr} \mathrm{K} \alpha \mathrm{X}$-ray radiation. The irradiated area was equal to $3.14 \mathrm{~mm}^{2}$. The $\sin ^{2} \psi$ method was used to elaborate the results for the determination of the residual stresses. 11 different values of the angle $\psi$ were used (varying from $-45^{\circ}$ to $+45^{\circ}$, with constant $\sin ^{2} \psi$ increments). Measurements were carried out along three axial lines of the axle, running at $0^{\circ}$, $120^{\circ}$ and $240^{\circ}$ (Fig. 2b) as suggested by EN 13261 [35]. Eighteen different measurement points were considered along each line. In depth measurements were also carried out at points 12 and 14 along the $0^{\circ}$ line, points 4 and 10 along the $120^{\circ}$ line and points $4,10,12$ and 14 along the $240^{\circ}$ line. These measurements were carried out by removing, step by step, a very thin layer of material using an electro-polishing device. A solution of acetic acid (94\%) and perchloric acid (6\%) was used for electro-polishing. Material removal from the axle surface was carried out up to the depth showing vanishing compressive residual stresses. Fig. 3a illustrates the full-scale axle under XRD measurement of residual stresses.

\subsubsection{Hole drilling method}

The hole drilling method was applied to the deep rolled axle following the suggestions by ASTM E837-08 [43]. Measurements were carried out at four different sections of the axle (A, B, C and $\mathrm{D}$ in Fig. $2 \mathrm{~b})$ at three different angular positions $\left(0^{\circ}, 120^{\circ}\right.$ and $240^{\circ}$ ) as suggested by EN 13261 [35] for railway axles. Fig. 3b shows the applied experimental set-up. It consisted of a strain-gage rosette having three radial measurement grids set in a Delta configuration; a frame with magnetic feet allowing the use of both the optical device for the correct centering of the tool holder; and subsequently the hole drilling tool itself. The latter was a $2 \mathrm{~mm}$ diameter carbide end mill driven by a high speed air turbine rotating at $50,000 \mathrm{rpm}$, in order to avoid the introduction of machining-induced residual stresses at the hole boundary [43]. Measurements were carried out step by step considering hole depths equal to $0.128 \mathrm{~mm}, 0.449 \mathrm{~mm}, 0.641 \mathrm{~mm}, 0.898 \mathrm{~mm}$, $1.283 \mathrm{~mm}$ and $1.881 \mathrm{~mm}$; and thus realizing a final cylindrical hole of about $2 \times 1.8 \mathrm{~mm}$ (Fig. $3 \mathrm{c}$ ). The experimental acquisitions were post-elaborated to determine the residual stresses along the longitudinal and circumferential directions of the axle.

\section{Finite element simulations}

\subsection{Definition of coverage in deep rolling}

A novel finite element technique was developed to simulate deep rolling. The aim of the finite element simulation is not only to represent the applied deep rolling, but also to systematically 


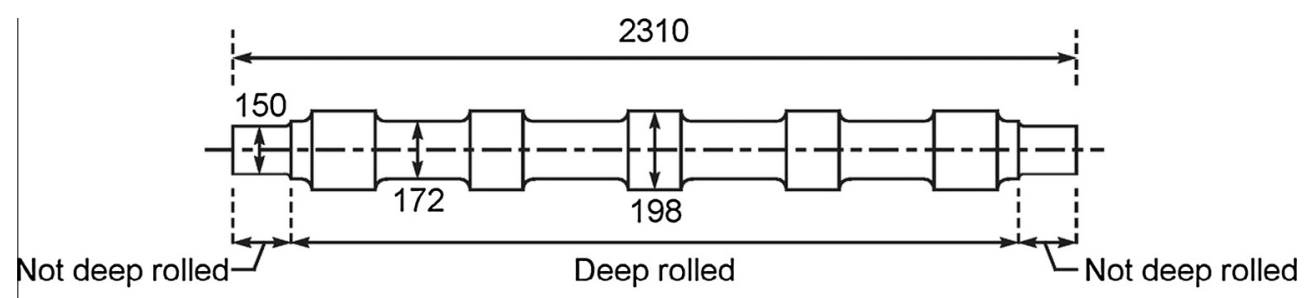

(a)

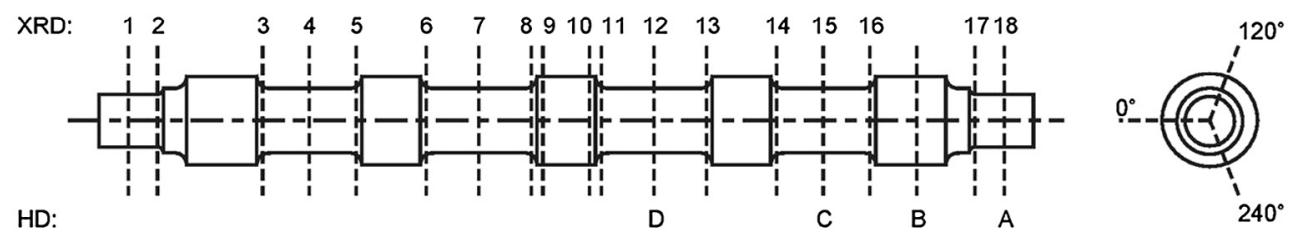

(b)

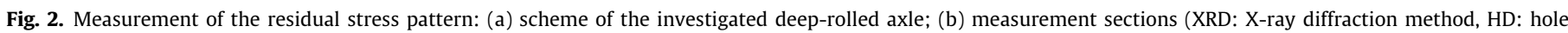
drilling method).

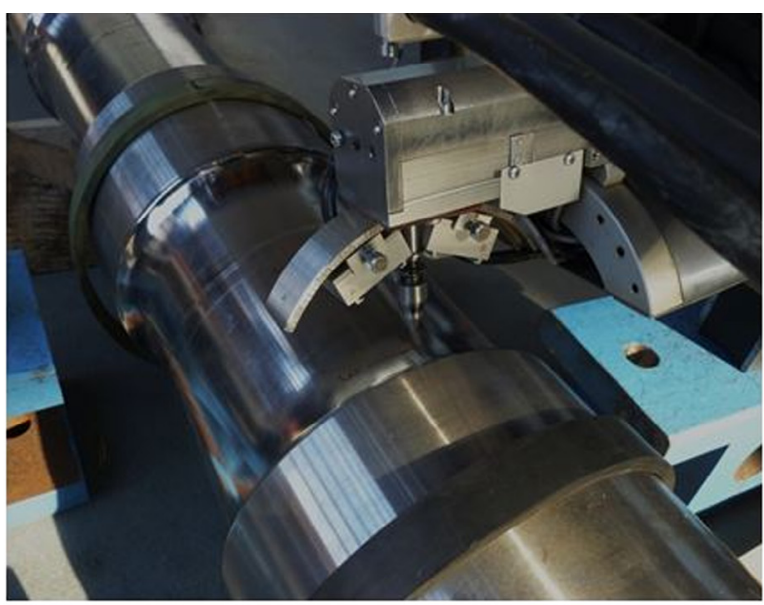

(a)

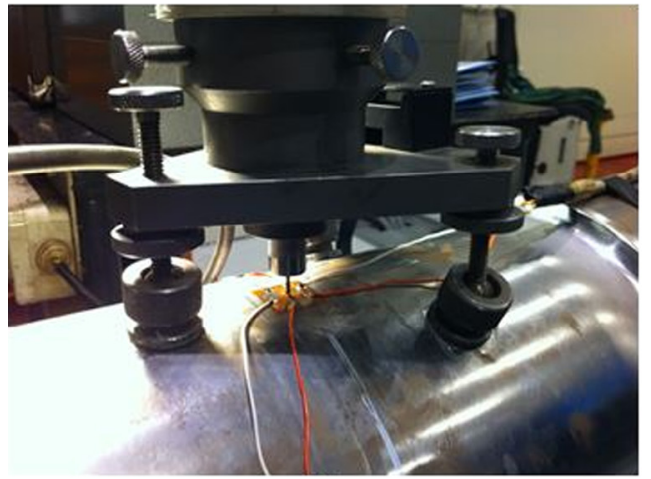

(b)

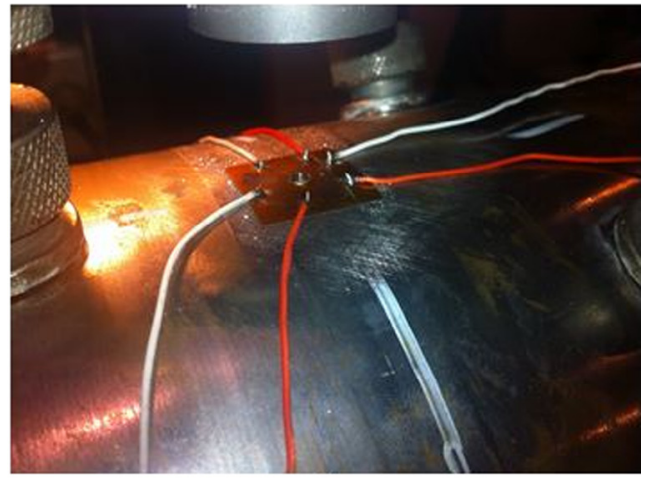

(c)

Fig. 3. Measurement of residual stresses: (a) full scale axle under XRD; (b) experimental set-up for the hole drilling method; (c) drilled hole.

study the effect of its key technological parameters: rolling pressure or force, roll geometry (roll tip radius in the present semicircular case) and rolling feed. A fourth parameter, i.e. "coverage", is defined here. Coverage, although not often mentioned as a technological parameter of deep rolling, is known to play an important role for other mechanical surface treatments like shot peening $[44,45]$. In shot peening, the coverage is defined as the ratio of the treated area to the whole target area, expressed as a percentage. A full coverage of $100 \%$ means that the whole target surface has been treated at least once. The same concept of coverage is also applicable to deep rolling. It is argued here that deep rolling coverage might vary when at least one of the three aforementioned key parameters varies. Coverage quantifies how many times surface points are treated during the process. Therefore, its incorporation 
is crucial to have a successful simulation and reliable interpretation of the results.

A schematic representation of deep rolling along with its key parameters is shown in Fig. 4a. Here, the aim is to study in-depth distribution of residual stress and induced hardening exactly beneath the roll tip (point A). The solid black line in Fig. 4a shows the current position of the roll on point $A$ and the corresponding surface deformation. Surface deformation can be characterized by the induced groove half span. Point A is treated for the first time when the roll is approaching and it is half-span far away, on point B. This situation is shown by dashed green line in Fig. 4a. The point of interest, A, is treated for the last time when the roll moves away and it is on point $\mathrm{C}$ : the dashed blue line in the figure shows this situation. Rolling feed, represented by " $F$ " in Fig. 4a, is the roll advancement per revolution. The ratio of half span "HS" to rolling feed determines how many times point $\mathrm{A}$ is treated by the roll. The following relation, therefore, defines deep rolling coverage:

$C \%=\left\{2 \times\left\lfloor\frac{H S}{F}\right\rfloor+1\right\} \times 100$

where $\lfloor x\rfloor$ denotes the largest integer less than or equal to $x$. Changes in rolling force and roll geometry vary the half span value appearing at the numerator. Rolling feed itself appears at the denominator. This correlation states that changes in rolling force, feed and roll geometry might end up with changing how many times surface points are treated. Accordingly, this phenomenon should be accurately introduced in finite element simulations.
A series of static finite element simulations of deep rolling (loading and unloading), applied to a representative target by a rigid roll, was conducted varying the applied force (between 4 and $19 \mathrm{kN}$ ) and the roll tip radius (between 1.5 and $10 \mathrm{~mm}$ ) to find out the half span value for each condition. Then, for each combination of rolling force, feed and roll tip radius, the pass number needed for a realistic simulation is calculated by the Eq. (2). For instance, the coverage for the schematic representation of Fig. 4a is $700 \%$. In other words, seven passes would be required for a realistic simulation of deep rolling in this case.

\subsection{Description of the model}

A block of $18 \mathrm{~mm}$ long, $18 \mathrm{~mm}$ wide and $15 \mathrm{~mm}$ high (Fig. 4b), after some preliminary analyses, was considered to be a suitable representative target. The same points, A, B and C, were inserted to make correspondence between Fig. $4 \mathrm{a}$ and $\mathrm{b}$. At the beginning of simulations, the roll was located at point B1 and in contact with the target. B1 was selected such that the segment B1-A1 is equal to the half span value for each combination of rolling force, feed and tip radius, while rolling course $\mathrm{B} 1-\mathrm{B} 2$ was considered to be $10 \mathrm{~mm}$ long. Simulations then started loading the target by the roll at point B1. Load was linearly increased from zero to the final value of the rolling force. Then it is kept constant while the roll is displaced from B1 to B2. Afterward, the roll is separated from the target and relocated to the same $X$ coordinate of point $B 1$ but with an increase of " $F$ " value along $Z$ direction, while there is no contact between the roll and the target. The same procedure of loading, rolling, separating and returning is performed for as many times

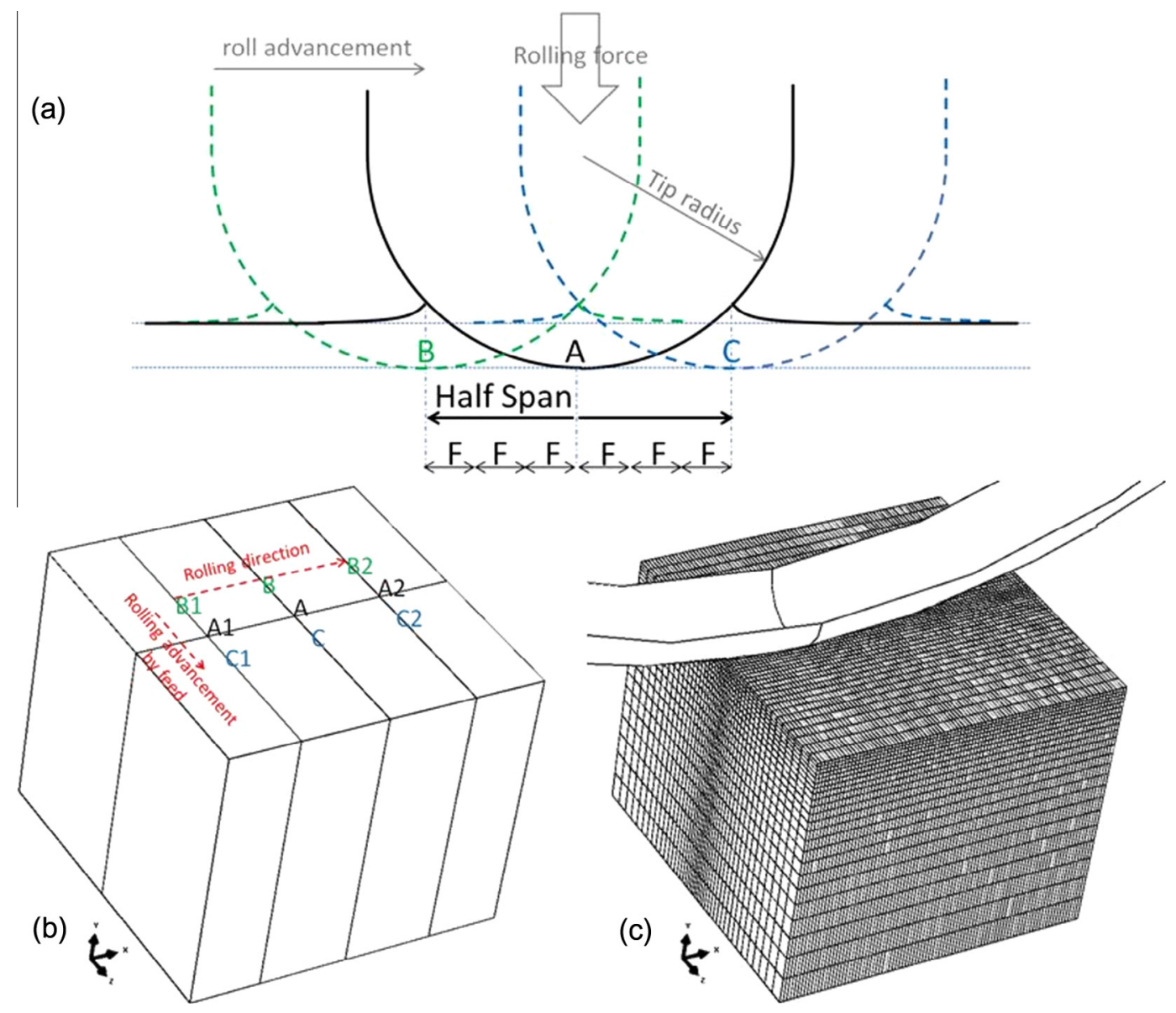

Fig. 4. (a) Schematic representation of deep rolling; (b) target block showing deep rolling course; (c) finite element model of the target block and the rigid roll. 
as needed to reach the specified coverage. For the case of Fig. $4 \mathrm{~b}$, for instance, the fourth rolling course was performed along A1$\mathrm{A} 2$ and the seventh i.e. the last one, along C1-C2. Accordingly, coverage of $700 \%$ is achieved along the A1-A-A2 segment, which is the plane of interest.

Using ABAQUS 6.10-1 [46], a three dimensional explicit finite element model was built to simulate the described strategy. The finite element model, discretized by 8-node linear hexahedral elements, is shown in Fig. 4c. The bottom side of the target was constrained in all degrees of freedom. The roll was modeled as an analytical rigid body, as it endures much less deformation than the target. The cyclic stress strain behavior shown in Fig. $1 \mathrm{a}$ and $\mathrm{b}$ was used to represent the material behavior in plastic regime. Eq. (1), along with the cyclic properties reported in Table 2, was used to extrapolate the stress-strain relationship to the plastic strain equal to 1 . Yielding of the material was represented by von Mises criterion, and the hardening behavior was considered to be isotropic. It was assumed that no hardening occurs for plastic strain higher than 1 . Surface to surface tangential frictionless contact was introduced between the external surfaces of the roller and the target. Frictionless contact was applied because deep rolling was performed with sufficient lubrication on the real axle. It should be mentioned the simulated target has a flat surface while the experiment was performed on a full scale railway axle with cylindrical shape. In fact, the curvature of the axle was overlooked in the simulation, as it is much higher than the curvature of the roll tip. After a mesh sensitivity analysis, $0.2 \mathrm{~mm}$ element size in the contact region proved to be small enough to achieve the convergence of results.

\section{Results and discussion}

\subsection{Surface residual stress}

The surface residual stress pattern obtained through XRD and HD is shown in Fig. 5a. The results along the $240^{\circ}$ line are shown for XRD measurement. Surface residual stresses were measured along the other two surface axial lines as well. Since the trends for the three investigated lines were nearly the same, the results for the $0^{\circ}$ and $120^{\circ}$ lines are not included. It can be seen that the residual stress state is not equi-biaxial as for other typical surface treatments such as shot peening [3], nitriding [47] or cold spray [48]. A longitudinal compressive residual stress twice larger than the circumferential one was generated. Principal stresses were also elaborated and are shown in Fig. 5a. The longitudinal and circumferential directions correspond, as expected, to principal directions. It is worth noticing that deep rolling was able to generate a uniform compressive residual stress pattern along the surface of the axle. Significantly different residual stress state can be seen in the not deep rolled bearing journals at the two ends.

The results obtained by HD have been also shown in Fig. 5a. In this case, the reported data for a given measurement section, are the average of the values acquired at $0^{\circ}, 120^{\circ}$ and $240^{\circ}$. Very high values of compressive residual stress have been measured in section B. Hole drilling method is rigorously applicable when the measured stress is less than one half of the yield stress of the material [43]. Since this condition is not fulfilled in the present case, the elaboration of the residual stresses by the usual formulas leads to an overestimation of the value of the residual stresses. Such overestimation of residual stress can be appreciated by comparing the results of XRD and HD for sections A, C and D. Higher compressive residual stress measured by HD could have been also attributed to the fact that data are not measured at the surface by HD, but at a depth equal to $0.128 \mathrm{~mm}$. Indeed no results can be obtained by this method at the surface itself. This might explain the difference of the XRD and HD stress values measured in sections $C$ and D where the difference is less marked but still relevant. The HD values obtained in section A, that was not rolled, are unexpected. Small amount of residual stresses have been also measured by XRD in section A. There might have been pre-existing residual stresses, likely due to the machining of the axle. In summary, some level of uncertainty exists for the surface residual stresses obtained by HD, as a result of high values of residual stress with respect to the yield stress.

\subsection{In-depth distribution of residual stress}

In-depth distribution of residual stress was determined, by XRD, at eight points. Four points correspond to the axle body and the other four correspond to the geometrical transitions from the body to the press-fit seats. Since the trends of in-depth residual stress distribution were repeatable, the results are presented for only two points (Fig. $5 \mathrm{~b}$ ): points 12 and 14 along the $0^{\circ}$ line, being representative of the body and the geometrical transitions, respectively. The similarity between the two measured patterns is worth noticing. Moreover, it can be seen that the state of residual stress is not equi-biaxial and it does not show a significant peak at the subsurface layers, unlike other surface treatments. The depth of the compressed layers generated by deep rolling is approximately $2.5 \mathrm{~mm}$.

A direct comparison between the in depth residual stress patterns obtained by XRD and HD can be made at point $12\left(0^{\circ}\right.$ line, measured by XRD) and section $\mathrm{D}$ (measured by HD). This comparison is shown in Fig. 5c. A clear difference between the XRD and the HD measurements can be noted near the surface up to the depth of $0.75 \mathrm{~mm}$. It can be interpreted in the light of the high values of the stresses with respect to the yield stress of the material and inapplicability of HD in this case. This interpretation is coherent with the fact that the difference tends to decrease in depth (deeper than $0.75 \mathrm{~mm}$ ) where the stresses are lower.

\subsection{Finite element simulations}

\subsubsection{Comparison with experiments and rolling feed effect}

Fig. 6a shows in-depth distribution of longitudinal residual stress for deep rolling with $7 \mathrm{kN}$ load, $2.5 \mathrm{~mm}$ roll tip radius and different rolling feeds. Among them, $f=0.15 \mathrm{~mm}$ corresponds to the performed experiment and can be used to compare the simulation results with XRD measurements, superimposed onto the plot. Comparison of the obtained residual stress distribution with the measured one shows satisfactory agreement, providing verification for the proposed approach.

Large feeds (larger than half span $\approx 0.7 \mathrm{~mm}$ in this case) tend to the coverage of $100 \%$. Even if it is not a suitable practical choice, the coverage of $100 \%$ was also simulated to complete the range of parametric study. Large feeds or $100 \%$ coverage signifies that the roll only moves along the segment A1-A2 shown in Fig. 4b. The result shows that, in this case, tensile residual stresses are developed on the surface. As feed decreases, the resulting coverage increases. Deep rolling processes characterized by the same coverage are shown with the same color from now on, to make the interpretation easier. Higher surface compressive residual stresses are developed by decreasing the feed. Compressive surface residual stress reaches a maximum for small enough feeds $(0.15-0.3 \mathrm{~mm}$, in this case) and then tends to decrease for further reduction of the feed. Moreover, decreasing feed, as far as it results in increasing coverage, increases the compressive residual stresses in the subsurface layers. The depth of compressed layer shows insignificant variation with the change in rolling feed. The trend of residual stress does not change appreciably for $F=0.6,0.5$ and $0.4 \mathrm{~mm}$, all resulting in the same coverage. 


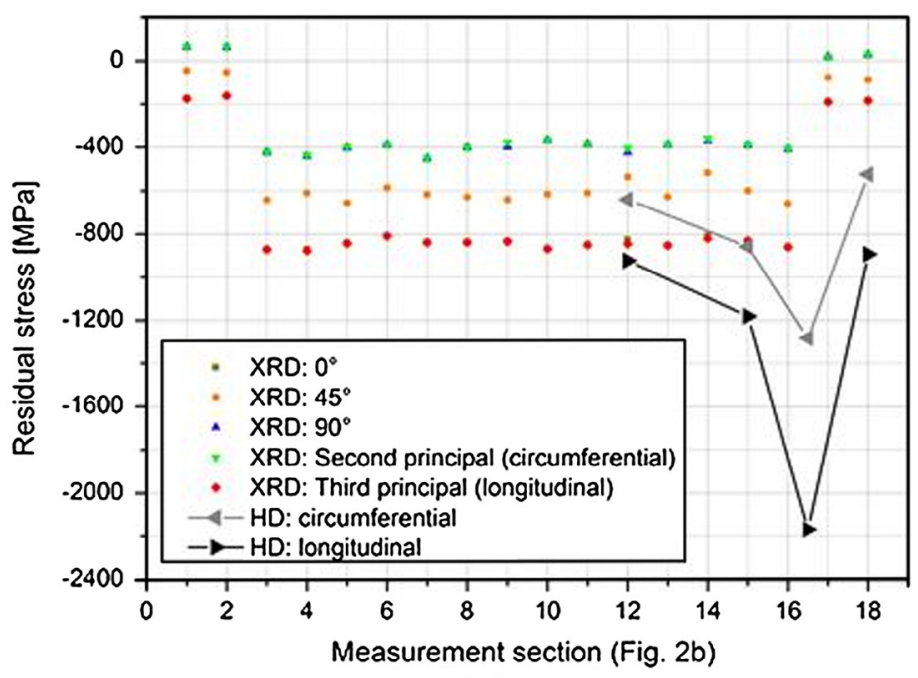

(a)

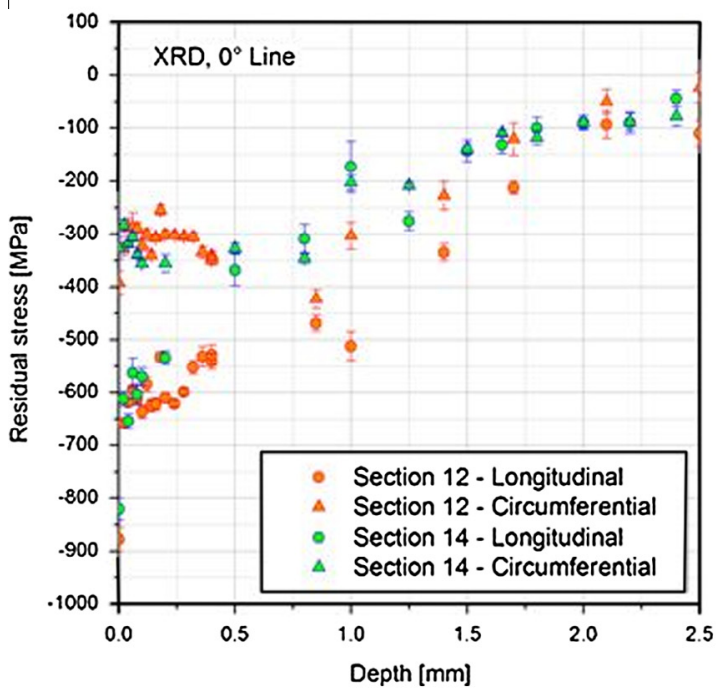

(b)

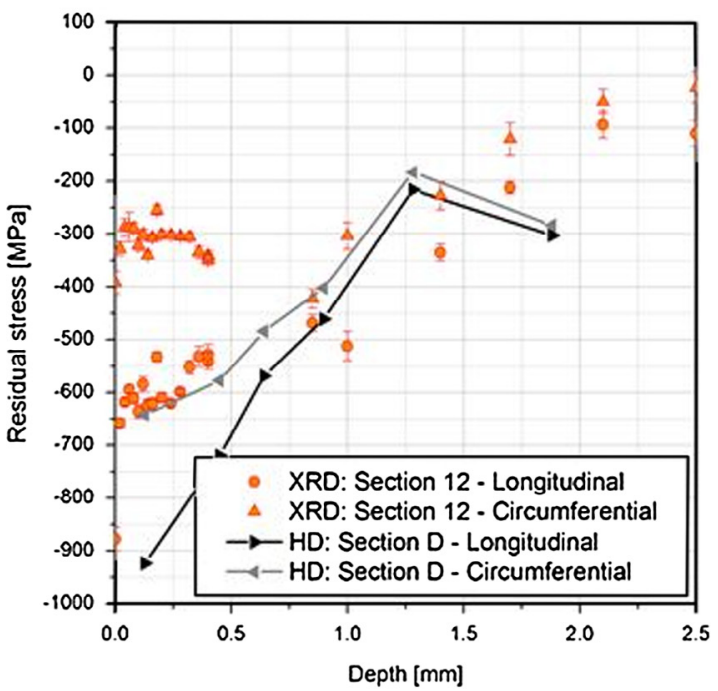

(c)

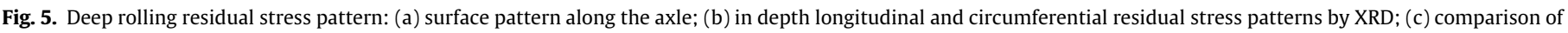
in depth longitudinal and circumferential residual stress patterns by XRD and HD.

The same inferences hold for the circumferential residual stress shown in Fig. 6b. The simulated circumferential residual stress deviates from measurement at the top surface layer of $0.2 \mathrm{~mm}$ deep. Beneath $0.2 \mathrm{~mm}$, however, the agreement is satisfactory. The deviation in the surface layer might be attributed to considering the roll as a rigid body. In this case, surface elements undergo higher circumferential expansion, higher unloading and, accordingly, less residual stress would remain after unloading.

The full width of the X-ray diffraction peak at half of its maximum value (FWHM) is able to accurately reflect some features of the surface work hardening, which may not be revealed by micro-hardness values $[3,4]$. FWHM is related to grain distortion, dislocation density and grain size, and can be assumed as an index of the hardening of the material. The distribution of the normalized FWHM defined as (FWHM - FWHM far-field $\left._{\text {f }}\right) / \mathrm{FWHM}_{\max }$, is shown in Fig. 6c. FWHM $M_{\max }$ and $\mathrm{FWHM}_{\text {far-field }}$ measured by XRD were $2.93^{\circ}$ and $1.9^{\circ}$, respectively. The distribution of normalized plastic strain $\left(\mathrm{PEEQ} / \mathrm{PEEQ}_{\max }\right)$.was also superimposed onto the graph. $\mathrm{PEEQ}_{\max }$ in the simulation was 0.788 . The satisfactory agreement between the two normalized parameters confirms that equivalent plastic strain can be used to represent the induced hardening during deep rolling and to estimate the depth of hardened layer. Maximum hardening occurs on the surface. In the present case, deep rolling was able to generate a more than $2 \mathrm{~mm}$ deep hardened layer.

The effect of rolling feed on in-depth distribution of equivalent plastic strain, as a suitable representative of the induced hardening, is shown in Fig. $6 \mathrm{~d}$. It can be seen that a smaller rolling feed, as far as it increases the coverage, would yield to higher plastic strains. The increment, in this case, is clearly due to the higher number of passes applied to the surface. For the same coverage, however, a lower rolling feed results in a lower plastic strain (see $F=0.4,0.5$ and $0.6 \mathrm{~mm}$ ). The reason is the following. Point $\mathrm{A}$, shown in Fig. $4 a$ and $b$, is treated three times with these three feed values, as the coverage is $300 \%$. In the second pass the roll tip is exactly on the point A. In this regard, the second pass is identical for all these 3 cases. The difference comes from the first and the third pass where the distance of the roll tip and point $A$ is equal to the feed. Increasing the feed increases this distance. Since higher plastic strain is induced at the points close to the groove edge as compared to the points close to the grove center, higher feed tends 


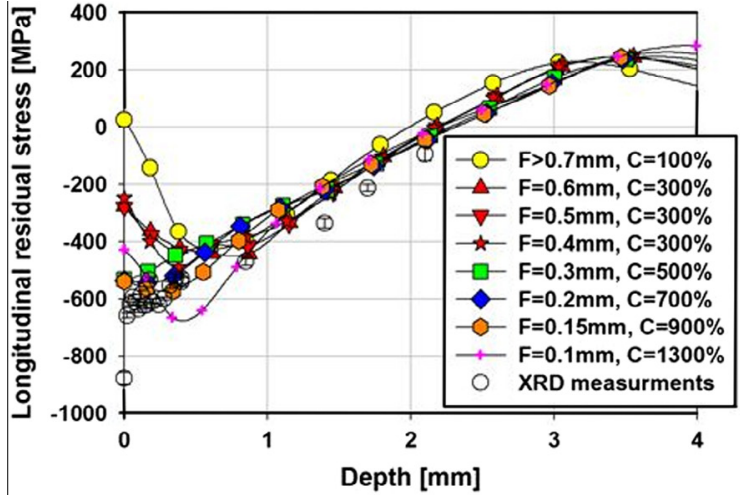

(a)

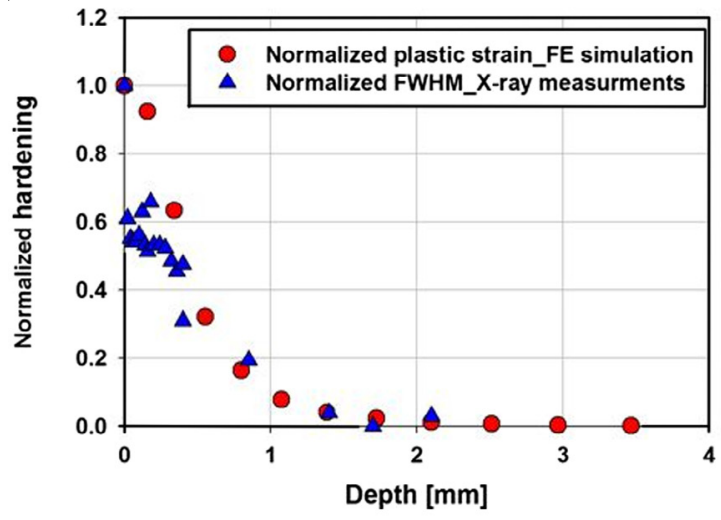

(c)

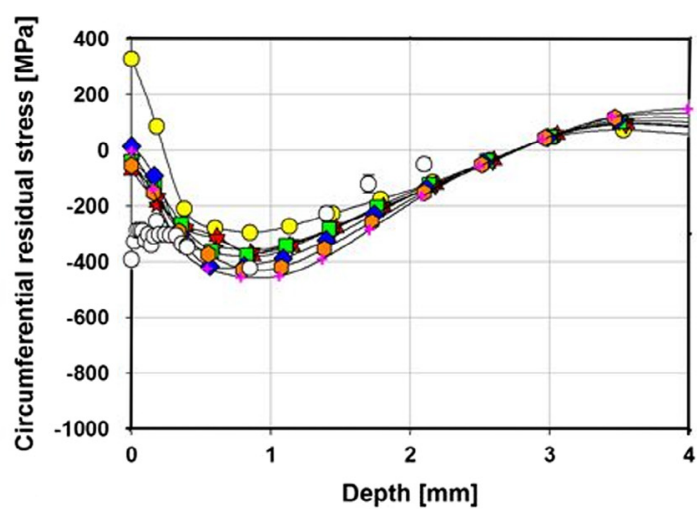

(b)

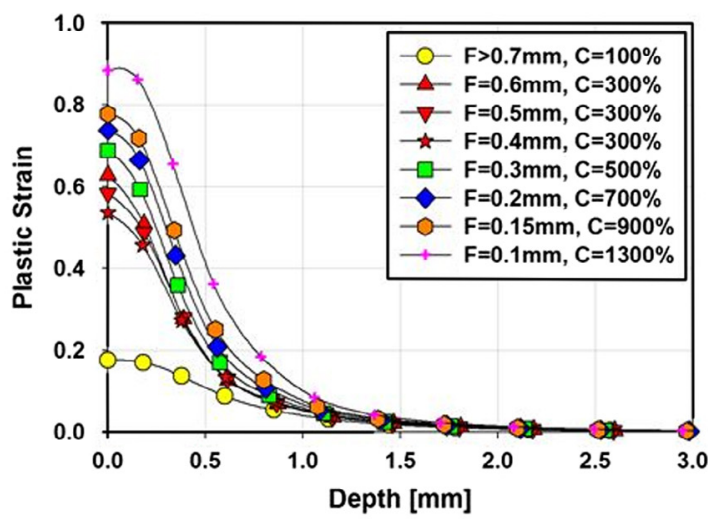

(d)

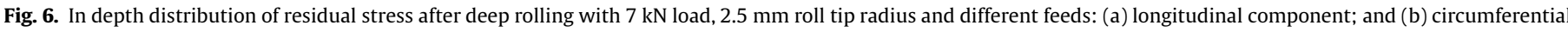

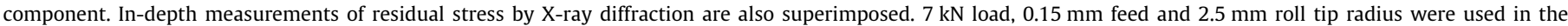

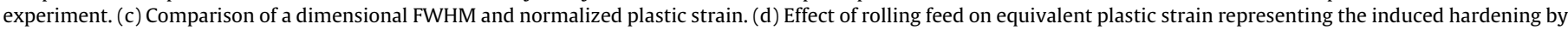
deep rolling.

to higher plastic strain and hardening when the coverage is the same.

Fig. 7 shows the distribution of longitudinal residual stress along the segment A1 A A2 after deep rolling with the same roll tip radius and force of the experiment, but for two different coverage values, $C=100 \%$ and $C=900 \%(f=0.15 \mathrm{~mm}) . C=900 \%$ matches with the experiment. Note that surface residual stress is tensile for $C=100 \%$; and compressive residual stress peak appears in the subsurface layer. This clearly does not correspond to the experimental measurement. Compressive residual stress peak moves toward surface for $C=900 \%$, matching well with the experimental measurement and confirming the significance of incorporating coverage in the finite element simulation. This result indeed questions the assumption that residual stress is affected by the rolling force only in the ramping up and down stage and not by the additional operation in the full load stage, previously adopted in simulations [19-21].

\subsubsection{Effect of rolling load}

Fig. 8a shows the in-depth distribution of longitudinal residual stress after deep rolling with $0.3 \mathrm{~mm}$ feed, $2.5 \mathrm{~mm}$ roll tip radius and different rolling loads (4-19 kN). Surface compressive residual stress increases, with increasing rolling load, up to a maximum level, that in this case was reached at $7 \mathrm{kN}$. Further increase in rolling load decreases surface compressive residual stress, and at extreme level tends to tensile rather than compressive residual stress state. The maximum compressive residual stress in the sub-surface layers follows the same trend, reaching to the maximum at $13 \mathrm{kN}$. Depth of compressed layer expands with increasing rolling load and eventually saturates at high rolling loads ( $13 \mathrm{kN}$ in this case).

The effect of rolling load on in-depth distribution of equivalent plastic strain is shown in Fig. 8b. Monotonic growth in plastic strain is observed for surface and subsurface points when rolling load increases. A higher increment can be seen in cases where increasing the load causes an increase in the coverage parameter too, denoted by symbol color change in the figure. The depth of the hardened layer, similar to the depth of compressed layer, eventually saturates at high rolling loads.

\subsubsection{Effect of roll geometry}

Fig. 8c shows in-depth distribution of longitudinal residual stress after deep rolling with $0.3 \mathrm{~mm}$ feed, $7 \mathrm{kN}$ load and different roll tip radii $(2.5-10 \mathrm{~mm})$. It was assumed that the roll tip has a semicircular geometry, as the one used in the experiment. Hence, roll tip radius (or roll thickness) represents the change in roll geometry. It can be seen that the form of near surface residual stress profile depends on the roll tip radius. The location of the maximum compressive residual stress shifts toward the surface as the roll tip radius increases (roll becomes thicker). In these cases, the profile is then followed by a plateau where residual stress is almost constant. Increasing roll tip radius would increase near surface compressive residual stress level (before plateau) if it is large enough to increase the coverage too. Otherwise, the same surface residual stress is obtained regardless of the roll tip radius. After the plateau, the residual stress profile is followed by a linear 


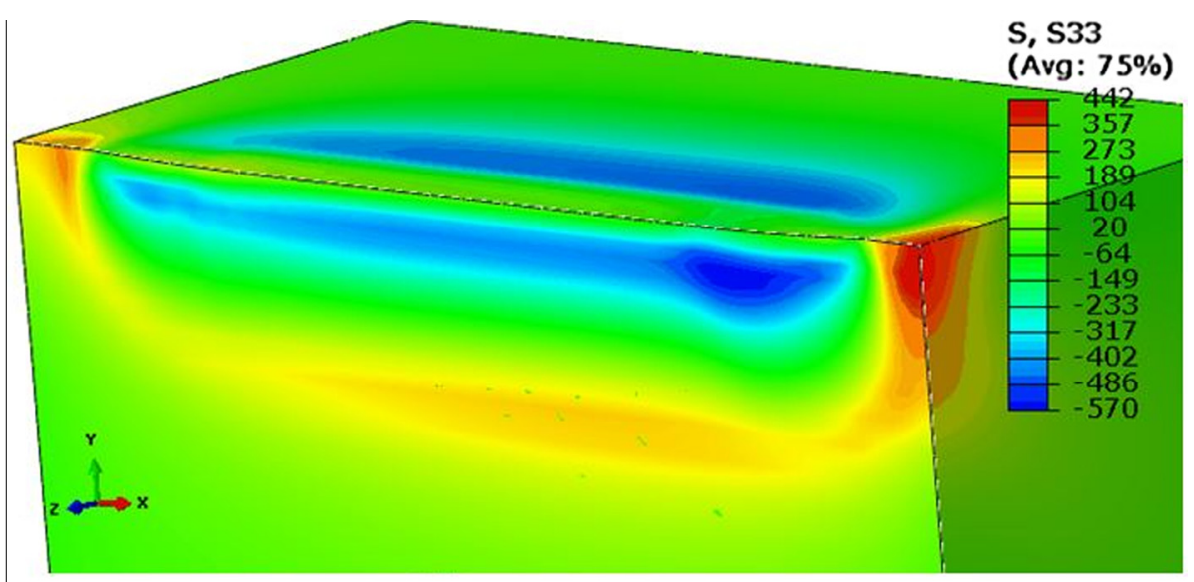

(a)

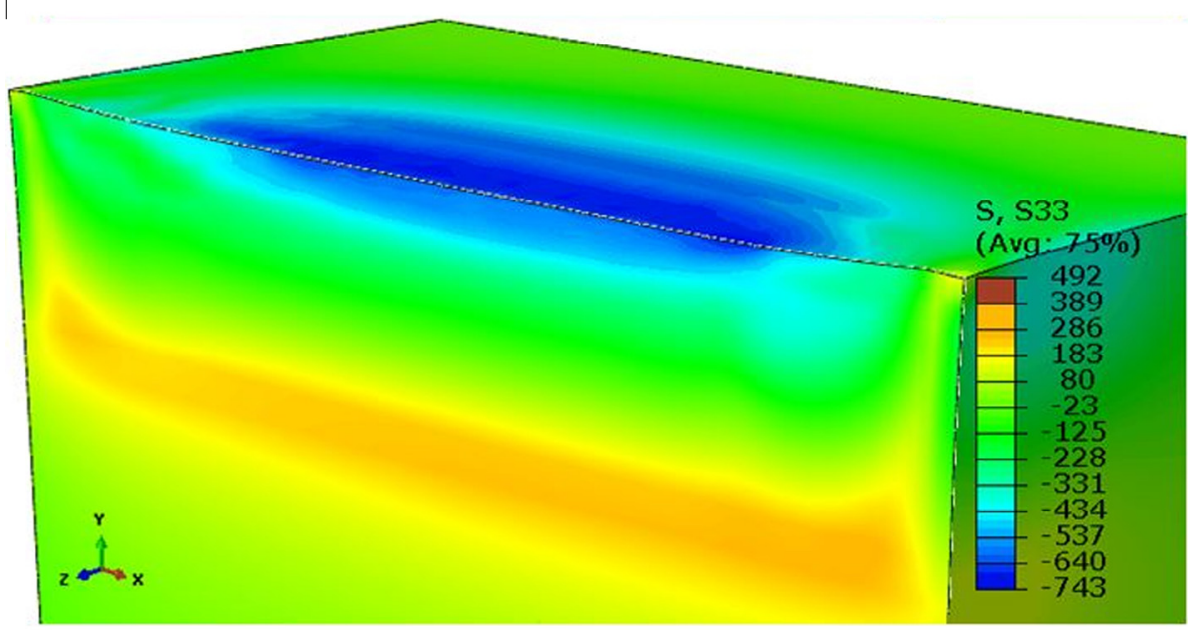

(b)

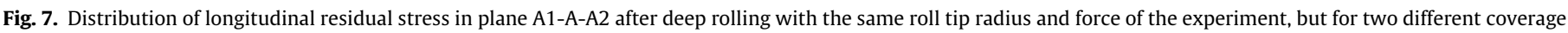
values, (a) $C=100 \%$ and (b) $C=900 \%$. The latter corresponds to the performed experiment.

reduction toward a tensile state in deeper regions. Changing roll tip radius does not have a tangible effect on the depth of compressed layers. The same holds for the induced hardening shown by the distribution of plastic strain in Fig. 8d. The induced hardening, nevertheless, at the top surface layer $(0.5 \mathrm{~mm})$ increases for the smaller roll tip radii (or thinner rolls). The rate of hardening increment increases at smaller radii. In fact, in the case of thinner rolls, the contact area decreases. The contact pressure would increase, given the load is constant. As a result, higher hardening is induced by thinner rolls in the near-surface layers.

\subsection{Fatigue crack propagation}

Compressive stresses are beneficial for fatigue and crack propagation lifetimes of mechanical components. The last section of the paper is focused on the analysis of the influence of compressive residual stresses on crack propagation lifetime of railway axles. An experimental study, based on fatigue crack growth (FCG) tests on deep rolled full-scale specimens [38] is used to validate the adopted crack growth model. A short summary of the experiments is given in the following.

The adopted full-scale specimen was specifically designed according to relevant standard [35], for the dedicated three point rotating bending bench with the capacity $250 \mathrm{kNm}$ (Fig. 9a). A portion of such a specimen was subjected to deep rolling treatment described in Section 2.4. After deep rolling, two semi-circular artificial defects were introduced into the deep rolled portion by EDM and at angular positions of $0^{\circ}$ and $180^{\circ}$. Three specimens were prepared with different initial artificial notch radii: $2 \mathrm{~mm}$, $3 \mathrm{~mm}$ and $4 \mathrm{~mm}$. These particular dimensions were chosen based on two reasons. First, a $2 \mathrm{~mm}$ deep initial notch is a good assumption of the largest in-service damage in terms of both corrosion-fatigue [49] and ballast impacts [50]. Second, the experimental and all the simulated residual stress profiles present their inversion, from compressive to tensile values, between 2 and $4 \mathrm{~mm}$ depths (Figs. 6a and 8a and c).

Specimens were then subjected to both constant amplitude (CA) loading and variable amplitude (VA) load sequences derived from a typical in-service load spectrum [51] and representative of about $57,000 \mathrm{~km}$ of high-speed service. Crack depth was monitored and measured during the tests by an ultrasonic phased array equipment and the application of the "crack tip diffraction" method [52].

\subsubsection{Validation of fatigue crack growth model}

A simple "no interaction" (i.e. not taking into account the load interaction effects) FCG algorithm was adopted, through the AFGrow v. 4.0012.15 package [53]. This software was chosen because it allows the introduction of arbitrary stress profiles representing the action of possible residual stresses. Stress intensity factor (SIF) values for residual stresses and in-service bending can be independently determined and then superimposed 


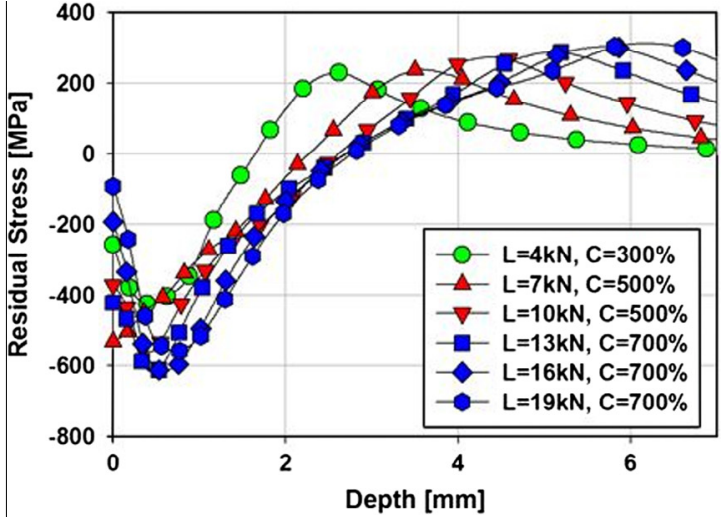

(a)

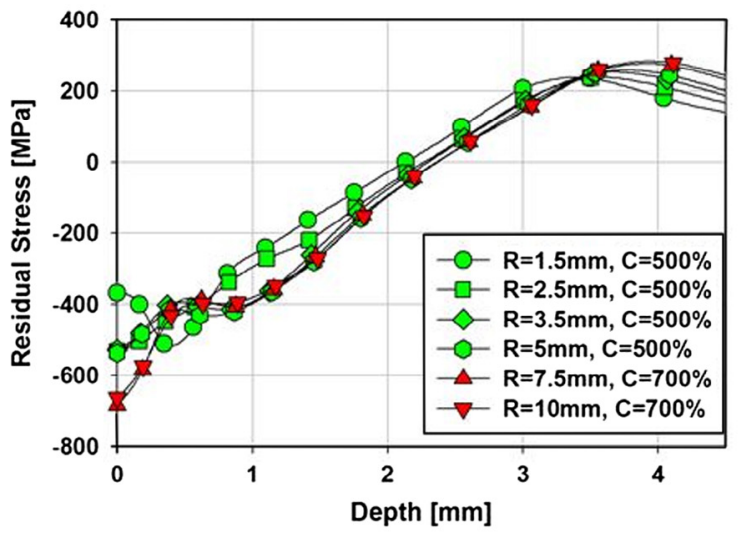

(c)

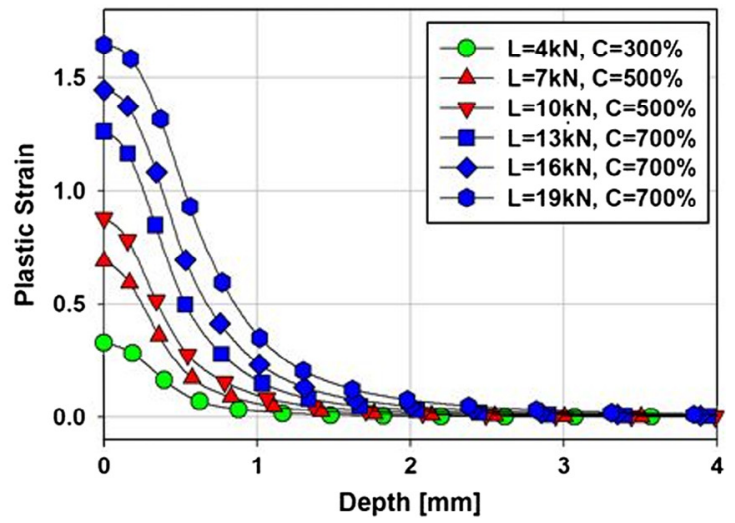

(b)

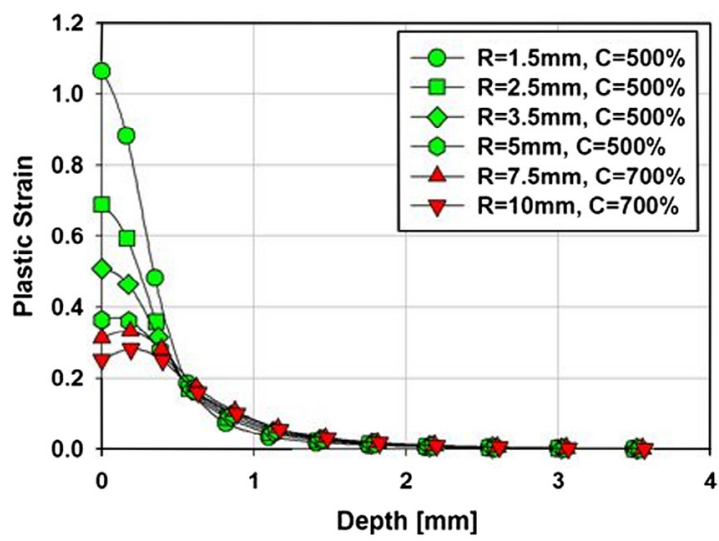

(d)

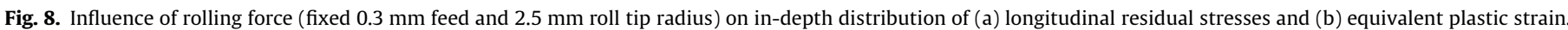
Influence of roll tip radius (fixed $0.3 \mathrm{~mm}$ feed and $7 \mathrm{kN}$ load) on in-depth distribution of (c) longitudinal residual stresses and (d) equivalent plastic strain.

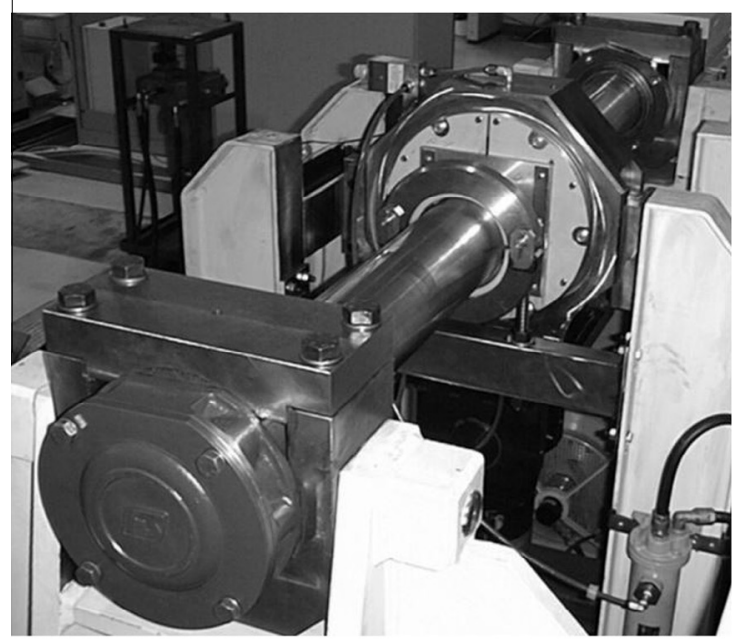

(a)

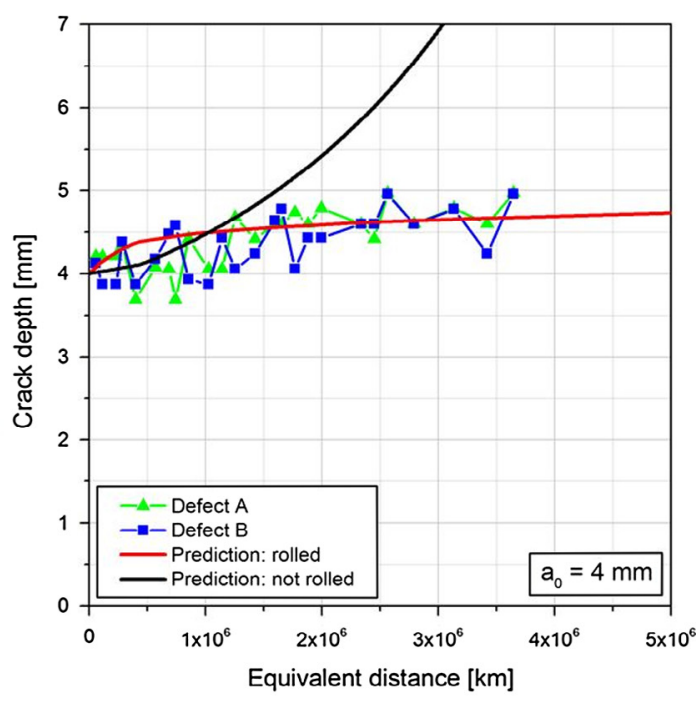

(b)

Fig. 9. Experimental fatigue crack growth tests on deep rolled full-scale specimens [38]: (a) adopted fatigue test bench; (b) initial notch radius equal to 4 mm.

during calculations. The SIF value related to residual stresses is treated as a "mean effect" varying the SIF ratio acting on the crack front because of applied in-service loads. From this point of view, a residual stress profile can be considered effective in terms of improving the fatigue strength, until the superposition of its consequent SIF value is able to maintain the crack driving force below the threshold SIF range of the operational stress ratio. It should be added that the SIF solution along the crack front is not only a function of the applied stress, but also a function of the dimension and shape of the crack. It is also a function of the geometrical boundary conditions of the cracked body. 
AFGrow is based on Nasgro equations [41], which were calibrated based on the experiment described in Section 4.4. The SIF solution for a circular rod containing a semi-circular transverse crack was adopted, considering all the different initial notch sizes of the tested specimens ( $R$ equal to 2,3 and $4 \mathrm{~mm}$ ) and the same block load sequences. In order to validate the FCG algorithm, the experimental deep rolling procedure described in Section 2.4 was considered. Fig. 9b shows the crack propagation results for the $4 \mathrm{~mm}$ deep initial notch case and compares them to the experimentally measured values. As can be seen, the FCG algorithm is well suited to describe experimental evidences. The same conclusion was drawn for the cases of $2 \mathrm{~mm}$ and $3 \mathrm{~mm}$ deep initial notches, not reported for the sake of brevity.

\subsubsection{Effect of deep rolling parameters on fatigue crack propagation}

The validated FCG algorithm was launched, applying all the residual stress profiles derived by $\mathrm{FE}$ simulations (Figs. 6a and 8a and c) to 2, 3 and $4 \mathrm{~mm}$ initial crack depths. This was aimed to achieve a first evaluation of the influence of the single technological parameter on crack propagation lifetime of railway axles. This means that analyses were carried out varying one parameter, while keeping the others fixed; and adopting the so-called "one-parameter-at-a-time" strategy [54]. Actually, this strategy is rarely the most efficient, because it cannot take into account the mutual interactions between parameters. It is applied to achieve an initial screening of their effects and as a basis for designing the more robust and efficient "Design of Experiments" (DoE) factorial plan [54] described later on.

Fig. 10 summarizes the obtained crack growth life. The results have been normalized with respect to the typical life of railway axles for high-speed applications, i.e. $30 \times 10^{6} \mathrm{~km}$. This means that a predicted normalized life equal to one denotes no crack propagation, while a life below one multiplied by $30 \times 10^{6}$ represents the number of kilometers needed to reach a crack depth or semi surface length equal to $10 \mathrm{~mm}$, which is here assumed as the failure of the axle.

Starting from the experimental deep rolling parameters (rolling load fixed at $7 \mathrm{kN}$ and roll tip radius at $2.5 \mathrm{~mm}$ ), Fig. 10a shows the influence of rolling feed. A $2 \mathrm{~mm}$ deep initial crack never propagates to failure except for a feed larger than $0.7 \mathrm{~mm}(C=100 \%)$.

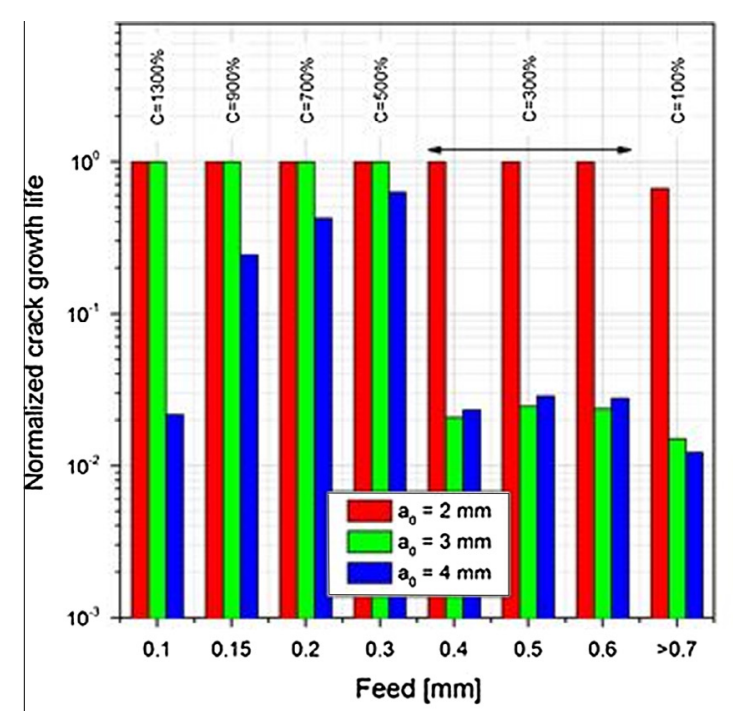

(a)

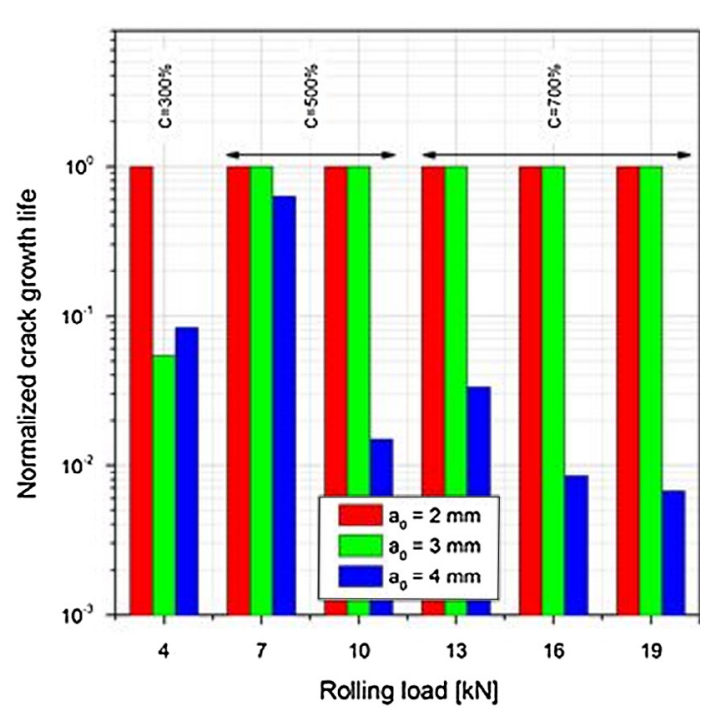

(b)

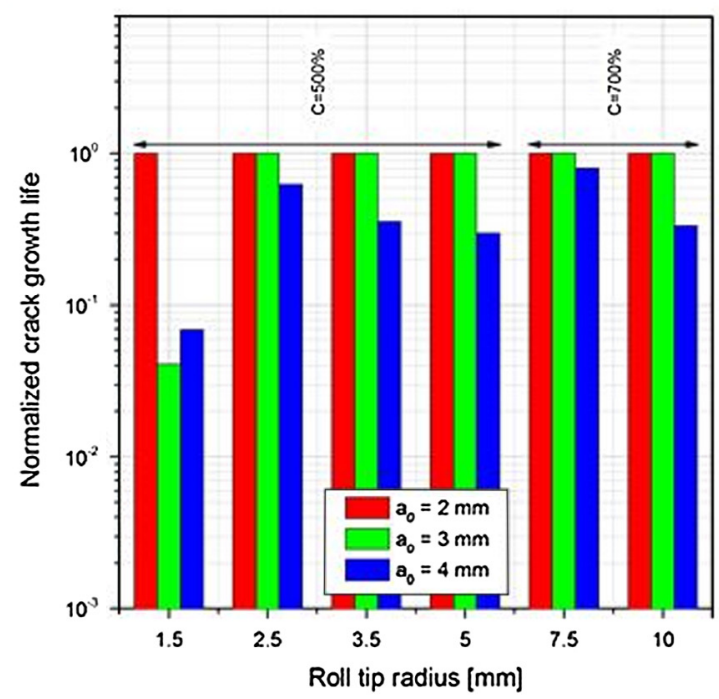

(c)

Fig. 10. Effect of the single deep rolling technological parameters on crack propagation lifetime: (a) feed; (b) rolling load; (c) roll tip radius. 
This result is confirmed by the full-scale experiment with feed equal to $0.15 \mathrm{~mm}$ where no crack propagation was observed. On the other hand, the failure for feed larger than $0.7 \mathrm{~mm}(C=100 \%)$ is attributed to the fact that both the surface and the deepest crack tips are characterized by a nearly null residual stress (see Fig. 6a). This questions the applicability of deep rolling with extremely low coverage.

A $3 \mathrm{~mm}$ deep initial crack does not propagate to failure for feed values lower or equal to $0.3 \mathrm{~mm}$ (coverage higher than $500 \%$ ). However, deep rolling is not able to prevent failure for larger feeds (coverage values lower than 500\%). This matches with our experimental observation of the full-scale test where, in order to get the $3 \mathrm{~mm}$ deep initial notches propagate, the applied load levels had to be increased by $175 \%$. Fig. 6 a shows that all cases present nearly the same tensile residual stress at the deepest crack tip. However, the propagating cracks are those that experienced a very low level of compressive residual stress at the surface.

Finally, a $4 \mathrm{~mm}$ deep initial crack always fails within the expected life. Nevertheless, the best results are achieved by a feed value between $0.15 \mathrm{~mm}(C=900 \%)$ and $0.3 \mathrm{~mm}(C=500 \%)$. The same behavior was observed in the full-scale experimental test where the $4 \mathrm{~mm}$ deep initial notches propagated under the adopted load spectrum. Feed equal to $0.1 \mathrm{~mm}(C=1300 \%)$ where the surface is treated extremely, resulted in the performance comparable to deep rolling with very low coverage value of $300 \%$ and less. This can be attributed to low level of the induced compressive residual stress at the surface. Deep rolling with extremely high coverage is characterized by higher compressive residual stresses in the subsurface layers and lower surface compressive residual stress. In order to balance high subsurface compressive residual stresses, higher tensile stresses are developed in the deepest region. This could be another factor that deteriorated the performance of deep rolling with extremely high coverage against deeper cracks.

In summary, the surface compressive residual stress seems to be more effective than subsurface compressive residual stresses to address the fatigue strength of the cracked deep rolled component for the range studied here. Propagation of a $2 \mathrm{~mm}$ deep crack, representative of real in-service damages, can be suitably prevented by the considered experimental deep rolling procedure. However, the adopted experimental deep rolling procedure might be optimized by applying a $0.3 \mathrm{~mm}$ feed providing coverage of $500 \%$.

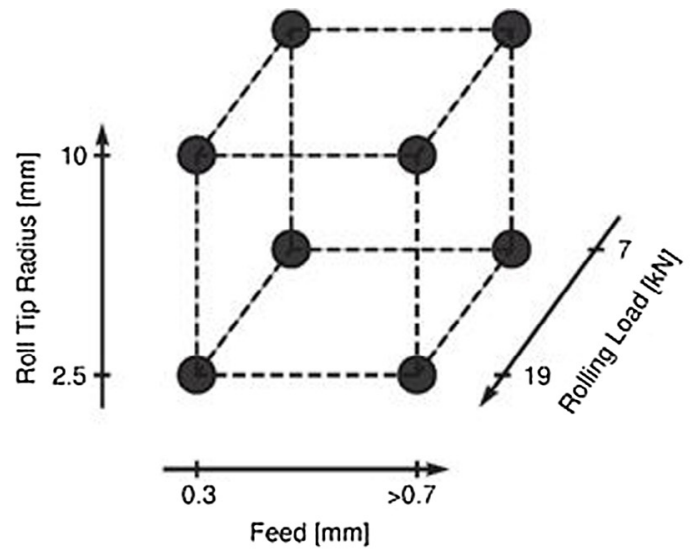

(a)

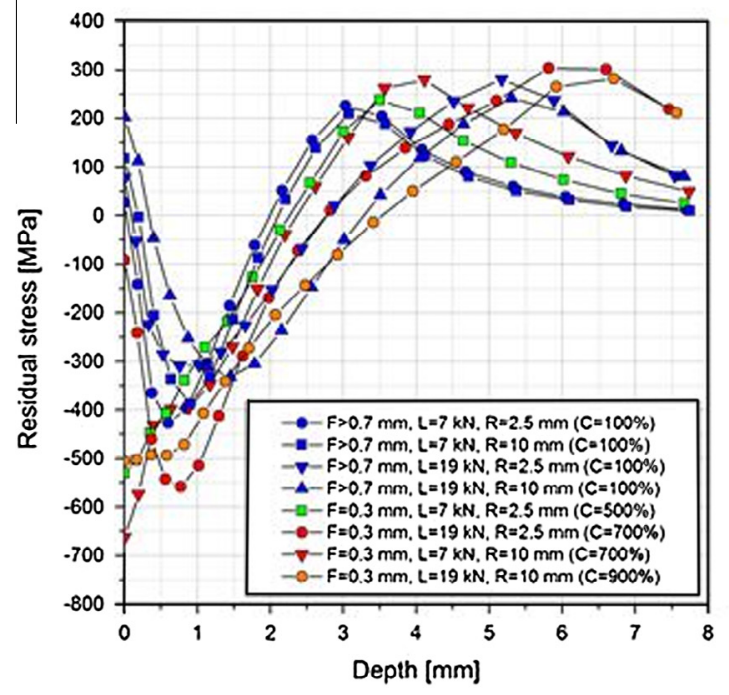

(b)

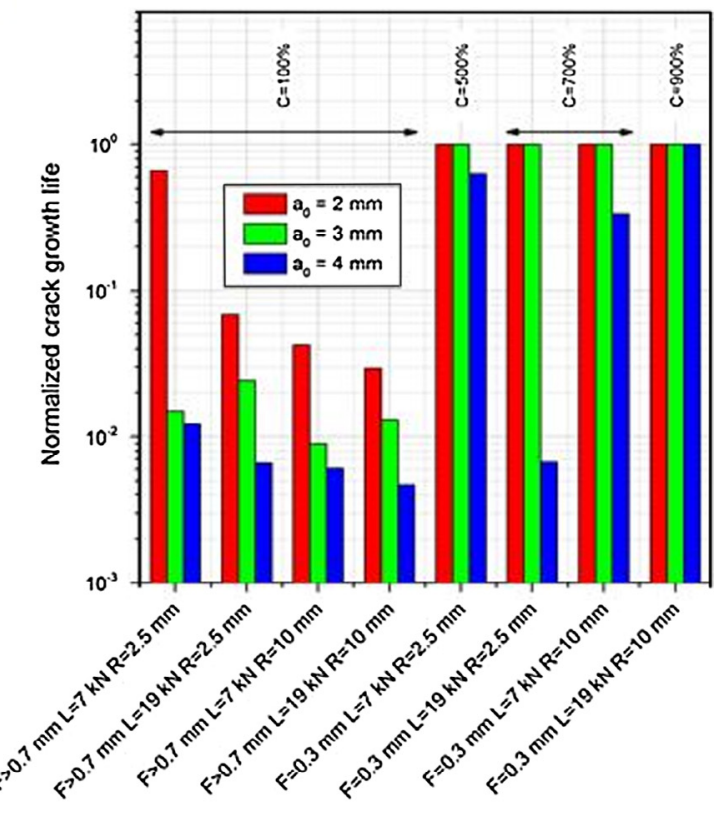

(c)

Fig. 11. "Design of Experiments" approach: (a) adopted $2^{k}$ full-factorial plan; (b) resulting residual stress profiles; (c) predicted fatigue crack growth lifetimes. 


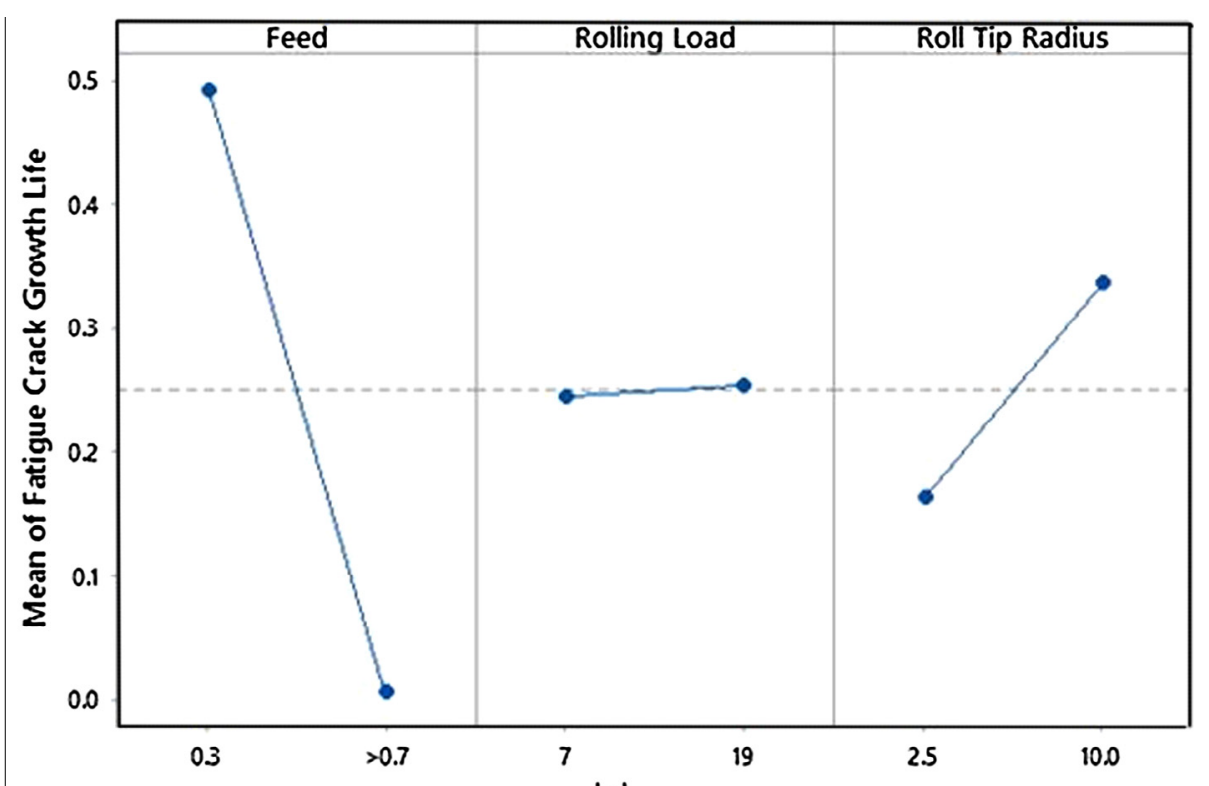

(a)

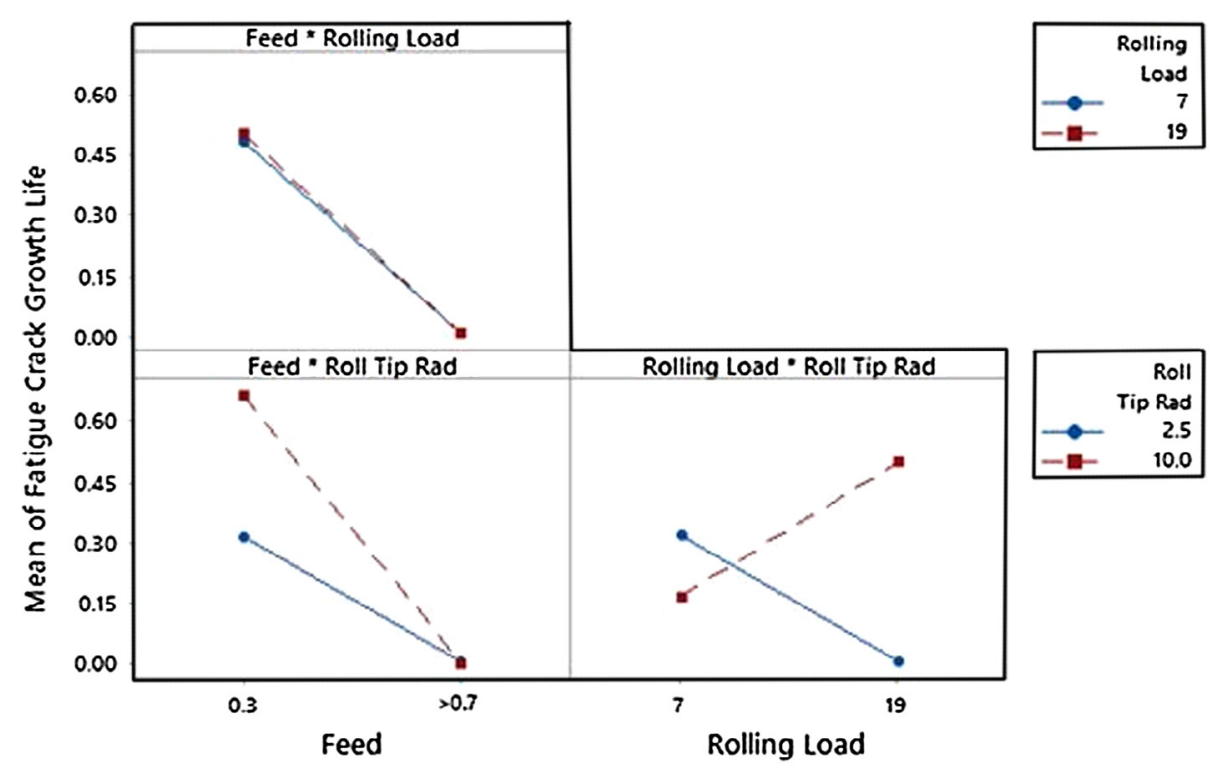

(b)

Fig. 12. "Main effects" (a) and "Interaction" (b) plots of deep rolling technological parameters.

Assuming a feed fixed at $0.3 \mathrm{~mm}$ (from the previous analysis) and a roll tip radius of $2.5 \mathrm{~mm}$ (from the experimental set-up), Fig. 10b shows the influence of rolling load. The results show that a $2 \mathrm{~mm}$ deep crack never propagates. A $3 \mathrm{~mm}$ deep crack propagates to failure only when the rolling load is lower than $7 \mathrm{kN}$, providing the coverage values lower than $500 \%$. Finally, a $4 \mathrm{~mm}$ deep crack always makes the axle fail, with a performance similar in all cases except for deep rolling with $7 \mathrm{kN}$, which tends to significantly longer life. The same arguments presented for the effect of rolling feed can be applied to justify the effect of rolling load too, with reference to the residual stress results of Fig. 8a. It can be seen from Fig. 8a that rolling load of $7 \mathrm{kN}$ resulted in the maximum compressive surface residual stress that plays a major role in governing the crack propagation behavior for the range of initial crack size considered in the present work. It can be concluded that the experimental deep rolling process is already optimized in terms of rolling load.
Finally, assuming a feed fixed at $0.3 \mathrm{~mm}$ and a rolling load at $7 \mathrm{kN}$, Fig. 10c shows the influence of roll tip radius on crack propagation life. Results are very similar to those previously discussed for feed and rolling force. The least performance of deep rolling in terms of crack propagation life occurred with the roll tip radius of $1.5 \mathrm{~mm}$ radius. This extremely thin roll indeed induced the lowest surface compressive residual stress (Fig. 8c). It can be also concluded that the experimental deep rolling process is already optimized in terms of roll tip radius.

The described analyses showed that the employed deep rolling parameters are likely just close to the optimized ones. Indeed, the adopted "one-parameter-at-a-time" strategy is computationally costly in terms of both FEM and crack propagation analyses. For example, assuming the three considered parameters and all their relevant levels, 288 scenarios should have been simulated. In order to improve the analysis a more robust DoE factorial plan [54] is considered which is described in the following section. 
4.4.3. "Design of Experiments" approach to optimize deep rolling

The DoE methodology is carried out adopting a $2^{k}$ full-factorial plan [54], where 2 is the number of levels considered for each of the considered $k$ factors, in order to study the key influencing factors of deep rolling. The levels of the considered factors are simultaneously varied in factorial design, allowing the study of mutual interactions which is not detectable when only single variations are applied.

Fig. 11a shows the adopted factorial plan. Three technological factors were considered. Each of them was assigned two different levels close to the ends of the performed parametric analysis: feed equal to 0.3 and larger than $0.7 \mathrm{~mm}$; rolling load equal to 7 and $19 \mathrm{kN}$ and roll tip radius equal to 2.5 and $10 \mathrm{~mm}$. Consequently, only eight combinations should be simulated and analyzed, instead of 288. Some of the results, needed as input, were already available from the previous sections, while the others were specifically simulated (Fig. 11b) and applied by the FCG algorithm to 2, 3 and $4 \mathrm{~mm}$ deep initial cracks (Fig. 11c). It can be seen that, the same correspondence, presented in Section 4.4.2, exists between the residual stress profile and the resulted crack growth life.

As the output for the DoE analysis, the normalized FCG lifetimes shown in Fig. 11c, for the case of a 4 mm deep initial crack, were considered. Results of the analysis are provided in terms of "main effects" and "interaction" plots to show differences among level means [54]. The "main effects" plot (Fig. 12a) provides the effect of the single factors, similar to the "one-parameter-at-a-time" strategy, but in a more robust way as the varying factor is analyzed against the mean level, and not a single fixed value. As can be seen, feed presents a strong influence on the fatigue crack growth life: the lower the feed, the longer the crack growth life. Rolling load, instead, does not seem to provide a significant influence, although higher deep rolling loads are preferable. Finally, the roll tip radius shows a mild influence: the higher the radius, the longer the predicted lifetime. In summery lower feeds, higher loads and thicker rolls in deep rolling can result in higher improvement against fatigue. It is interesting to note that lower feeds, higher loads and thicker rolls results in higher level of deep rolling coverage. Deep rolling coverage seems to act as the master parameter in deep rolling and can efficiently characterize different deep rolling processes.

The "interaction" plot (Fig. 12b) provides the interactive effect of factors on the crack growth life. The interaction between feed and rolling load (upper left diagram in Fig. 12b) is not significant since the corresponding curves are parallel and, in this case almost coincident. Variation of feed between 0.3 and a value larger than $0.7 \mathrm{~mm}$ causes significant changes in the fatigue crack growth life, but the simultaneous variation of the rolling load between 7 and $19 \mathrm{kN}$ does not contribute to significantly change the same results. A lower feed, and thus higher coverage, is preferable in deep rolling.

The interaction between rolling load and roll tip radius (lower right diagram in Fig. 12b) seems to be significant, since the corresponding curves clearly intersect. To get the best output at lower load $(7 \mathrm{kN})$, thinner roll $(2.5 \mathrm{~mm}$ tip radius) should be adopted, whereas at very high rolling load $(19 \mathrm{kN})$, thicker roll $(10 \mathrm{~mm}$ tip radius) is preferred. The reason is that deep rolling with very high load and thin rolls results in extremely high level of coverage that can deteriorate the beneficial effects of deep rolling as discussed in Section 4.4.2.

Finally, the interaction between feed and roll tip radius (lower left diagram in Fig. 12b) seems to be rather uncertain since the corresponding curves are not parallel, but they do not clearly intersect as well. To get the best output at lower feed $(0.3 \mathrm{~mm})$ thicker roll ( $10 \mathrm{~mm}$ tip radius) should be adopted. For the feed value larger than $0.7 \mathrm{~mm}$ or coverage of $100 \%$, no differences can be observed. This means that for the coverage of $100 \%$ where the surface point is treated once roll thickness does not play a significant role.
The optimized technological configuration, for deep rolling railway axles made of EA4T steel, seems to be a $0.3 \mathrm{~mm}$ feed, a $19 \mathrm{kN}$ rolling load and a $10 \mathrm{~mm}$ roll tip radius. This particular configuration could not be identified by the "one-parameter-at-a-time" strategy. Moreover, the optimized configuration seems to be the only one (Fig. 11c) able to prevent FCG for 2, 3 and $4 \mathrm{~mm}$ deep cracks. In summary, lower feed, higher load and thicker roll, all resulting in higher level of coverage, are preferable for deep rolling. Deep rolling coverage seems to be able to effectively serve as a master parameter in deep rolling.

\section{Concluding remarks}

Deep rolling with $7 \mathrm{kN}$ load, $0.15 \mathrm{~mm} / \mathrm{rev}$ feed and $5 \mathrm{~mm}$ thick roll with a semi-circular tip, was successfully applied to a full-scale railway axle made of medium strength steel. The induced residual stresses were measured by X-ray diffraction and hole drilling. A realistic finite element simulation of deep rolling was developed and verified by the experimental measurements. A parametric study was performed to investigate the effect of rolling force, rolling feed and roll geometry on the distribution of residual stresses and the resultant fatigue crack propagation life. The following conclusions can be drawn based on the obtained results:

- The deep rolling induced longitudinal compressive residual stress was in the order of the ultimate tensile strength of the material and almost twice higher than the circumferential residual stress.

- The depth of the compressed and hardened layers generated by deep rolling was approximately $2.5 \mathrm{~mm}$. In-depth distribution of residual stress, measured by XRD, did not show significant peaks at the subsurface layers. The same trend was obtained by hole-drilling method, although the values were overestimated in the surface layer of $0.75 \mathrm{~mm}$ deep.

- Normalized FWHM from XRD and plastic strain from FEM were found to be in a good agreement with each other, confirming that plastic strain can be used to represent the induced hardening by deep rolling.

- Decreasing deep rolling feed increases the coverage, and yield to higher compressive residual stresses and higher hardening. Extremely high coverage, nevertheless, would result in lower surface compressive residual stresses. The depth of compressed layer shows insignificant variation with the change in rolling feed.

- Increasing deep rolling load increases the coverage, and yield to higher surface compressive residual stress up to a maximum level; and higher hardening. Further increase in rolling load decreases surface compressive residual stress and at extreme level tends to tensile rather than compressive surface residual stress state.

- Increasing roll tip radius increases the coverage and yield to higher near surface compressive residual stress level and lower hardening.

- The surface compressive residual stress was shown to be more effective than the subsurface compressive residual stresses to prevent/retard the crack propagation in a deep rolled component for the examined initial crack size range of 2-4 mm.

- Lower feeds, higher loads and thicker rolls, all resulting in higher coverage, can result in higher improvement against fatigue crack propagation. Variation of feed was shown to have the strongest effect on the resultant crack growth life. Although higher level of deep rolling coverage is preferable, extremely high coverage can deteriorate the performance of deep rolled components 
against fatigue crack propagation. Deep rolling coverage seems to act as the master parameter in deep rolling and can efficiently characterize different deep rolling processes.

- As a general rule of thumb, adopting deep rolling feed to get a coverage level of $500-900 \%$, while avoiding too high rolling loads and too thin rolls, can induce a suitable compressive residual stress distribution; and effectively prevent/retard fatigue crack propagation.

\section{Acknowledgements}

The present research was carried out in the frame of the MARAXIL Project co-funded by Regione Lombardia (ID 16973, Rif. $\mathrm{n}^{\circ}$ MAN-15). The authors would like to thank Prof. S. Beretta, Dr. D. Regazzi (Dept. Mechanical Engineering, Politecnico di Milano), Mr. S. Cantini (Lucchini RS SpA), Dr. M. Luke, Dr. I. Varfolomeev (Fraunhofer IWM) for the useful help and discussions.

\section{References}

[1] V. Schulze, Modern Mechanical Surface Treatment: States, Stability, Effects, Wiley, 2006.

[2] I. Altenberger, Deep rolling - the past, the present and the future, Int. Conf. Shot Peen. (2005) 144-155.

[3] S.M. Hassani-Gangaraj, A. Moridi, M. Guagliano, A. Ghidini, M. Boniardi, The effect of nitriding, severe shot peening and their combination on the fatigue behavior and micro-structure of a low-alloy steel, Int. J. Fatigue 62 (2014) 6776, http://dx.doi.org/10.1016/j.ijfatigue.2013.04.017.

[4] S.M. Hassani-Gangaraj, A. Moridi, M. Guagliano, A. Ghidini, Nitriding duration reduction without sacrificing mechanical characteristics and fatigue behavior: the beneficial effect of surface nano-crystallization by prior severe shot peening, Mater. Des. 55 (2014) 492-498.

[5] S.M. Hassani-Gangaraj, A. Moridi, M. Guagliano, Fatigue properties of a lowalloy steel with a nano-structured surface layer obtained by severe mechanical treatments, Key Eng. Mater. 577-578 (2013) 469-472, http://dx.doi.org/ 10.4028/www.scientific.net/KEM.577-578.469.

[6] R.K. Nalla, I. Altenberger, U. Noster, G.Y. Liu, B. Scholtes, R.O. Ritchie, On the influence of mechanical surface treatments-deep rolling and laser shock peening-on the fatigue behavior of $\mathrm{Ti}-6 \mathrm{Al}-4 \mathrm{~V}$ at ambient and elevated temperatures, Mater. Sci. Eng. A 355 (2003) 216-230.

[7] P. Juijerm, I. Altenberger, Effect of high-temperature deep rolling on cyclic deformation behavior of solution-heat-treated $\mathrm{Al}-\mathrm{Mg}-\mathrm{Si}-\mathrm{Cu}$ alloy, Scr. Mater. 56 (2007) 285-288.

[8] I. Altenberger, B. Scholtes, U. Martin, H. Oettel, Cyclic deformation and near surface microstructures of shot peened or deep rolled austenitic stainless steel AISI 304, Mater. Sci. Eng. A 264 (1999) 1-16.

[9] N. Tsuji, S. Tanaka, T. Takasugi, Effect of combined plasma-carburizing and deep-rolling on notch fatigue property of Ti-6Al-4V alloy, Mater. Sci. Eng. A 499 (2009) 482-488, http://dx.doi.org/10.1016/j.msea.2008.09.008.

[10] I. Altenberger, R.K. Nalla, Y. Sano, L. Wagner, R.O. Ritchie, On the effect of deeprolling and laser-peening on the stress-controlled low- and high-cycle fatigue behavior of Ti-6Al-4V at elevated temperatures up to $550{ }^{\circ} \mathrm{C}$, Int. J. Fatigue 44 (2012) 292-302.

[11] K.H. Kloos, B. Fuchsbauer, J. Adelmann, Fatigue properties of specimens similar to components deep rolled under optimized conditions, Int. J. Fatigue 9 (1987) 35-42.

[12] G.H. Majzoobi, K. Azadikhah, J. Nemati, The effects of deep rolling and shot peening on fretting fatigue resistance of Aluminum-7075-T6, Mater. Sci. Eng. A 516 (2009) 235-247.

[13] N. Tsuji, S. Tanaka, T. Takasugi, Evaluation of surface-modified Ti-6Al-4V alloy by combination of plasma-carburizing and deep-rolling, Mater. Sci. Eng. A 488 (2008) 139-145, http://dx.doi.org/10.1016/j.msea.2007.11.079.

[14] I. Altenberger, E.A. Stach, G. Liu, R.K. Nalla, R.O. Ritchie, An in situ transmission electron microscope study of the thermal stability of near-surface microstructures induced by deep rolling and laser-shock peening, Scr. Mater. 48 (2003) 1593-1598, http://dx.doi.org/10.1016/S1359-6462(03)00143-X.

[15] I. Nikitin, B. Scholtes, H.J. Maier, I. Altenberger, High temperature fatigue behavior and residual stress stability of laser-shock peened and deep rolled austenitic steel AISI 304, Scr. Mater. 50 (2004) 1345-1350.

[16] P. Juijerm, I. Altenberger, Residual stress relaxation of deep-rolled Al-Mg-Si$\mathrm{Cu}$ alloy during cyclic loading at elevated temperatures, Scr. Mater. 55 (2006) $1111-1114$.

[17] I. Nikitin, M. Besel, Residual stress relaxation of deep-rolled austenitic steel,

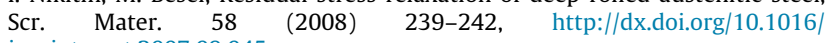
j.scriptamat.2007.09.045.

[18] W.Y. Chien, J. Pan, D. Close, S. Ho, Fatigue analysis of crankshaft sections under bending with consideration of residual stresses, Int. J. Fatigue 27 (2005) 1-19.
[19] P. Spiteri, S. Ho, Y.L. Lee, Assessment of bending fatigue limit for crankshaft sections with inclusion of residual stresses, Int. J. Fatigue 29 (2007) 318-329.

[20] K.S. Choi, J. Pan, Simulations of stress distributions in crankshaft sections under fillet rolling and bending fatigue tests, Int. J. Fatigue 31 (2009) 544-557.

[21] K.S. Choi, J. Pan, Effects of pressure-sensitive yielding on stress distributions in crankshaft sections under fillet rolling and bending fatigue tests, Int. J. Fatigue 31 (2009) 1588-1597.

[22] EN13103, Railway Applications - Wheelsets and Bogies - Non Powered Axles Design Method, CEN, 2012.

[23] EN13104, Railway Applications - Wheelsets and Bogies - Powered Axles Design Method, CEN, 2012.

[24] R.A. Smith, S. Hillmansen, Monitoring fatigue in railway axles, in: 13th Int. Wheel. Congr. Roma, Italy, 2001.

[25] Transportation Safety Board of Canada, Main track derailment: Canadian national train No.G-894-31-14, Railway Investigation Report R01Q0010, 2001.

[26] A. Watson, Implication of axle damage onto the structural integrity of axles, ESIS TC24 Meet, Berlin, 2010.

[27] S. Beretta, M. Carboni, G. Fiore, A. Lo Conte, Corrosion-fatigue of A1N railway axle steel exposed to rainwater, Int. J. Fatigue 32 (2010) 952-961.

[28] U. Zerbst, M. Vormwald, C. Andersch, K. Mädler, M. Pfuff, The development of a damage tolerance concept for railway components and its demonstration for a railway axle, Eng. Fract. Mech. 72 (2005) 209-239.

[29] S. Cantini, S. Beretta, Structural Reliability Assessment of Railway Axles, LRSTechno Ser, 4, 2011.

[30] A.F. Grandt, Fundamentals of Structural Integrity: Damage Tolerant Design and Nondestructive Evaluation, Wiley, 2003.

[31] T. Makino, T. Kato, K. Hirakawa, Review of the fatigue damage tolerance of high-speed railway axles in Japan, Eng. Fract. Mech. 78 (2011) 810-825.

[32] K. Hirakawa, M. Kubota, On the fatigue design method for high-speed railway axles, Proc. Inst. Mech. Eng. Part F: J. Rail Rapid Transit. 215 (2001) 73-82.

[33] J.W. Zhang, L.T. Lu, K. Shiozawa, G.D. Cui, W.H. Zhang, Fatigue properties of oxynitrocarburized medium carbon railway axle steel in very high cycle regime, Int. J. Fatigue 32 (2010) 1805-1811.

[34] J.W. Zhang, L.T. Lu, K. Shiozawa, X.L. Shen, H.F. Yi, W.H. Zhang, Analysis on fatigue property of microshot peened railway axle steel, Mater. Sci. Eng. A 528 (2011) 1615-1622.

[35] EN 13261, Railway Application - Wheelsets and Bogies - Axles - Product Requirements, CEN, 2011.

[36] ASTM E8/E8M-11, Standard Test Methods for Tension Testing of Metallic Materials, ASTM, 2011.

[37] ASTM E606/E606M-12, Standard Test Methods for Strain-Controlled Fatigue Testing, ASTM, 2012.

[38] D. Regazzi, S. Beretta, M. Carboni, An investigation about the influence of deep rolling on fatigue crack growth in railway axles made of a medium strength steel, Eng. Fract. Mech. 131 (2014) 587-601, http://dx.doi.org/10.1016/ j.engfracmech.2014.09.016.

[39] R. Pippan, The growth of short cracks under cyclic compression, Fatigue Fract. Eng. Mater. Struct. 9 (1987) 319-328, http://dx.doi.org/10.1111/j.14602695.1987.tb00459.x.

[40] M. Carboni, L. Patriarca, D. Regazzi, Determination of DKth by compression pre-cracking in a structural steel, J. ASTM Int. 6 (2009) 1-13.

[41] R. Forman, R. McClung, NASGRO 4.0, Fracture Mechanics and Fatigue Crack Growth Analysis Software, Reference Manual, 2002.

[42] V. Hauk, Structural and Residual Stress Analysis by Nondestructive Methods, Elsevier, 1997.

[43] ASTM E837-08, Standard Test Method for Determining Residual Stresses by the Hole-Drilling strain-Gage Method, ASTM, 2008.

[44] S.M.H. Gangaraj, M. Guagliano, G.H. Farrahi, An approach to relate shot peening finite element simulation to the actual coverage, Surf. Coat. Technol. 243 (2014) 39-45, http://dx.doi.org/10.1016/j.surfcoat.2012.03.057.

[45] S.M. Hassani-Gangaraj, M. Guagliano, G.H. Farrahi, Finite element simulation of shot peening coverage with the special attention on surface nanocrystallization, Proc. Eng. 10 (2011) 2464-2471.

[46] Dassault Systemes, ABAQUS 6.10-1 User's manual, 2010.

[47] S.M. Hassani-Gangaraj, M. Guagliano, Microstructural evolution during nitriding, finite element simulation and experimental assessment, Appl. Surf. Sci. 271 (2013) 156-163, http://dx.doi.org/10.1016/j.apsusc.2013.01.154.

[48] A. Moridi, S.M. Hassani-Gangaraj, M. Guagliano, S. Vezzu, Fracture and Fatigue, vol. 7, Springer, 2014, http://dx.doi.org/10.1007/978-3-319-00765-6.

[49] N. Gravier, J. Viet, A. Leluan, Prédiction de la durée se vie des essieux-axes ferroviaires, Rev Générale Des Chemins Fer 3 (1999) 33-40.

[50] RSSB T728, Research Project, Impact of corrosion upon the high cycle fatigue properties of GB axle steel, 2011.

[51] S. Beretta, M. Carboni, S. Cervello, Design review of a freight railway axle: fatigue damage versus damage tolerance, Mat-Wiss U Werkstofftech (2011) 42.

[52] J. Krautkrämer, H. Krautkrämer, Ultrasonic Testing of Materials, SpringerVerlag, 1990

[53] AFGrow v. 4.0012.15, User's manual, 2008.

[54] D.C. Montgomery, Design and Analysis of Experiments, John Wiley \& Sons, 2008. 